Guidelines for Developing Habitat-based Threatened and Endangered Species Population Goals on Army Installations

Ann-Marie Shapiro and Matthew Hohmann

October 2005

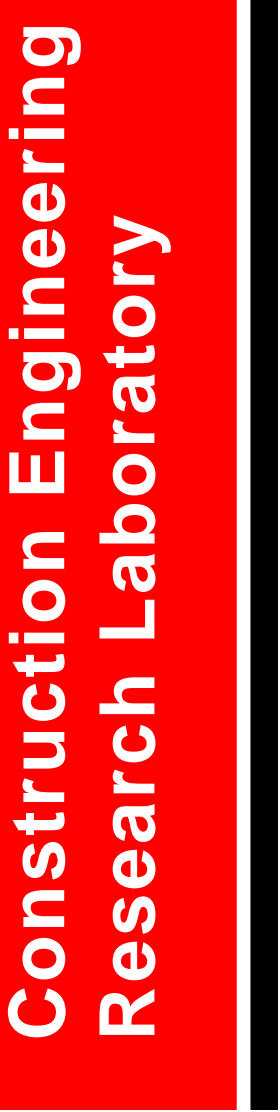




\section{Guidelines for Developing Habitat-based Threatened and Endangered Species Population Goals on Army Installations}

Ann-Marie Shapiro

Center for Ecological Management of Military Lands

Colorado State University

Fort Collins, CO 80523-1490

Matthew Hohmann

Construction Engineering Research Laboratory

PO Box 9005

Champaign, IL 61826-9005

Final Report

Approved for public release; distribution is unlimited.

Prepared for U.S. Army Corps of Engineers

Washington, DC 20314-1000

Under

Work Unit 008B44 
ABSTRACT: This document provides an overview of species-habitat modeling approaches, including recent recommendations and criticisms of model shortcomings. Rather than provide an exhaustive treatment of species-habitat modeling, this report provides enough information that an installation could hire or supervise an expert to conduct appropriate modeling, and anticipate and avoid common pitfalls and errors associated with current approaches. The overview is based on a hierarchical structure for organizing species-habitat modeling approaches. Modeling approaches are grouped into three classes, based on data requirements, effort, expense, technical difficulty, application uses, and output characteristics.

DISCLAIMER: The contents of this report are not to be used for advertising, publication, or promotional purposes. Citation of trade names does not constitute an official endorsement or approval of the use of such commercial products. All product names and trademarks cited are the property of their respective owners. The findings of this report are not to be construed as an official Department of the Army position unless so designated by other authorized documents.

DESTROY THIS REPORT WHEN IT IS NO LONGER NEEDED. DO NOT RETURN IT TO THE ORIGINATOR. 


\section{Contents}

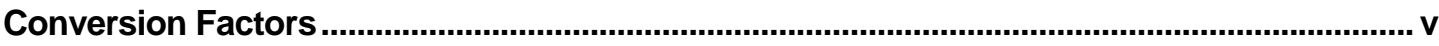

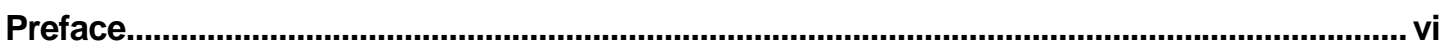

1 Introduction

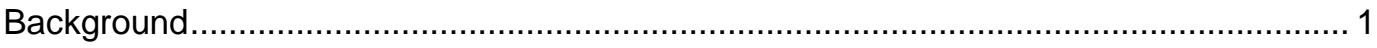

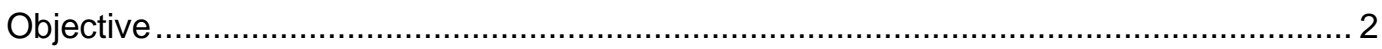

Approach …w.

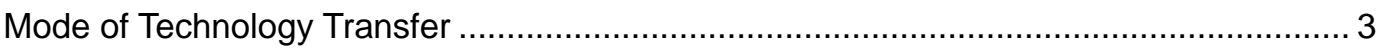

2 Introduction to Three General Classes of Species-Habitat Modeling ................................ 4

Class I - Predicting Species Presence and Absence........................................................ 4

Class II - Predicting Species Abundance and Quantitative Response to Habitat.............. 4

Class III - Quantifying Species Demographics in Habitat ................................................... 5

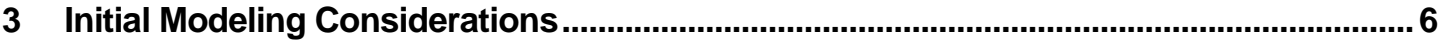

4 An Overview of Logical Approaches to Species-Habitat Modeling ..................................... 8

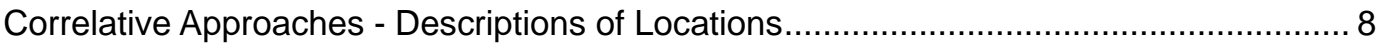

Resource Selection Approaches - Comparisons of Habitat Use by Animals..................... 9

Knowledge-based Approaches .............................................................................. 9

5 Quantification and/or Description of Habitat ............................................................. 11

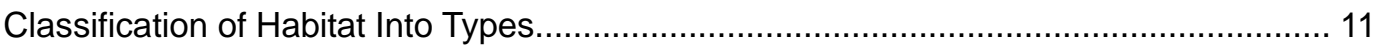

Assessing Degree of Habitat Suitability or Quality ................................................... 12

Spatially Explicit Habitat Evaluation...................................................................... 14

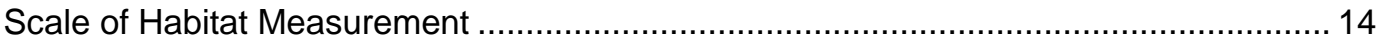

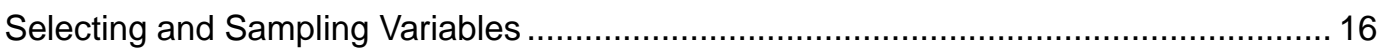

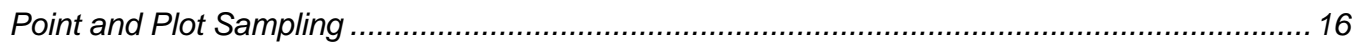

Remotely Sensed Data as Habitat Variables ................................................................... 17

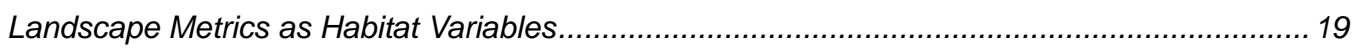

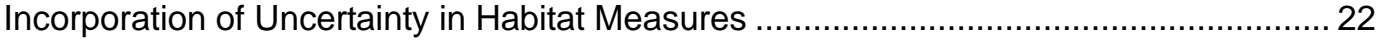

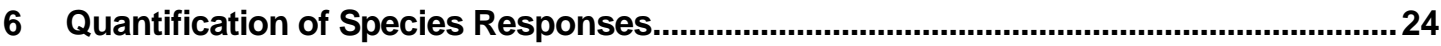

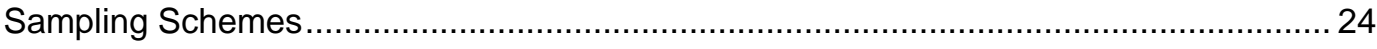

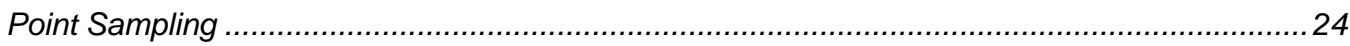

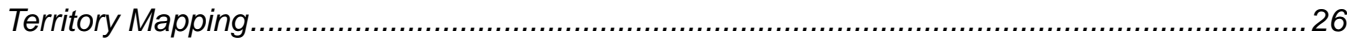


Estimating Abundance and Density of Species Populations …..................................... 27

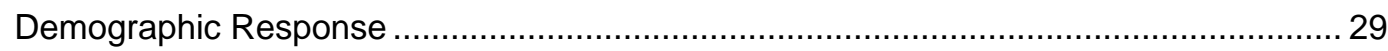

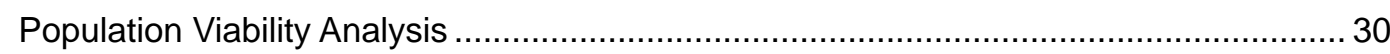

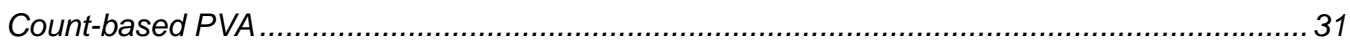

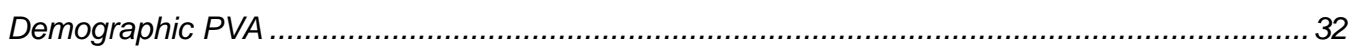

7 Modeling the Relationship Between Habitat and Species ................................................37

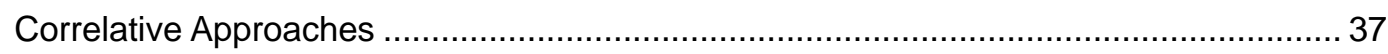

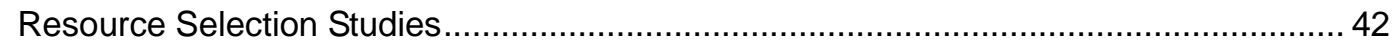

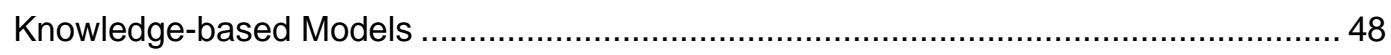

An Alternative Paradigm - Modeling Constraints with CART ........................................ 50

Mapping Spatial Data and Understanding Spatial Structure in Data .............................. 50

8 Sources of Error and the Importance of Accuracy Assessment .......................................52

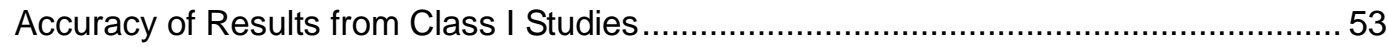

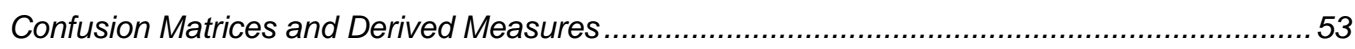

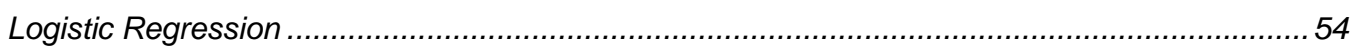

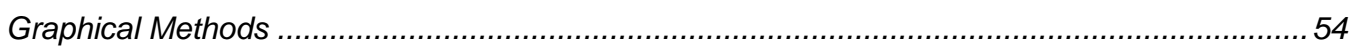

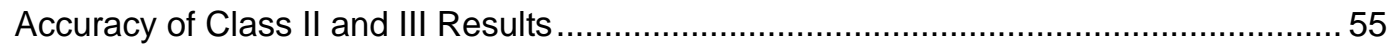

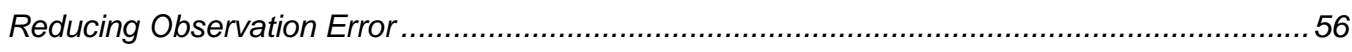

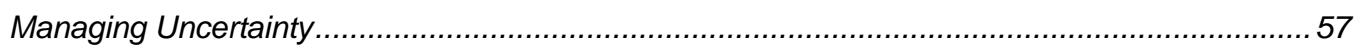

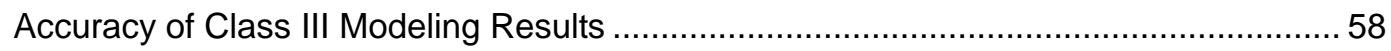

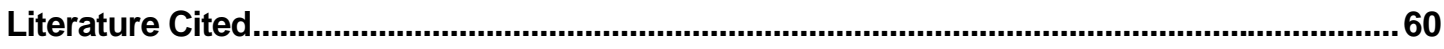

Appendix A: A Checklist for Study Design and Validation Considerations When

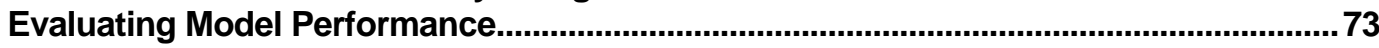

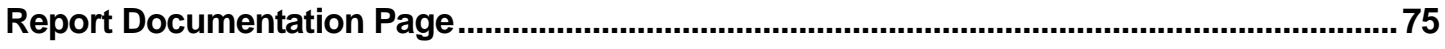




\section{Conversion Factors}

Non-SI* units of measurement used in this report can be converted to SI units as follows:

\begin{tabular}{|c|c|c|}
\hline Multiply & By & To Obtain \\
\hline acres & $4,046.873$ & square meters \\
\hline cubic feet & 0.02831685 & cubic meters \\
\hline cubic inches & 0.00001638706 & cubic meters \\
\hline degrees (angle) & 0.01745329 & radians \\
\hline degrees Fahrenheit & $(5 / 9) \times\left({ }^{\circ} \mathrm{F}-32\right)$ & degrees Celsius \\
\hline degrees Fahrenheit & $(5 / 9) \times\left({ }^{\circ} \mathrm{F}-32\right)+273.15$ & kelvins \\
\hline feet & 0.3048 & meters \\
\hline gallons (U.S. liquid) & 0.003785412 & cubic meters \\
\hline horsepower (550 ft-lb force per second) & 745.6999 & watts \\
\hline inches & 0.0254 & meters \\
\hline kips per square foot & 47.88026 & kilopascals \\
\hline kips per square inch & 6.894757 & megapascals \\
\hline miles (U.S. statute) & 1.609347 & kilometers \\
\hline pounds (force) & 4.448222 & newtons \\
\hline pounds (force) per square inch & 0.006894757 & megapascals \\
\hline pounds (mass) & 0.4535924 & kilograms \\
\hline square feet & 0.09290304 & square meters \\
\hline square miles & $2,589,998$ & square meters \\
\hline tons (force) & $8,896.443$ & newtons \\
\hline tons $(2,000$ pounds, mass $)$ & 907.1847 & kilograms \\
\hline yards & 0.9144 & meters \\
\hline
\end{tabular}

\footnotetext{
*Système International d'Unités ("International System of Measurement"), commonly known as the "metric system."
} 


\section{Preface}

This study was conducted for the Department of the Army, Office of the Director of Environmental Programs under A896, "Base Facilities Environmental Quality;" Work Unit 008B44, "Viable Population Goals for TES." The technical monitor was Bill Woodson, DAIM-ED.

The work was completed through the Land and Heritage Conservation Branch (CNC) of the Installations Division (CN), Construction Engineering Research Laboratory (CERL). The CERL Principal Investigator was Matthew Hohmann. Part of this work was done by Ann-Marie Shapiro under contract from the Center for Ecological Management of Military Lands, Colorado State University, Fort Collins, CO. The technical editor was Gloria J. Wienke, Information Technology Laboratory Champaign. Dr. Lucy Whalley is Chief, CEERD-CN-C, and L. Michael Golish is Acting Chief, CEERD-CN. The associated Technical Director was William D. Severhinghaus, CEERD-CV-T. The Acting Director of CERL is Dr. Ilker Adiguzel.

CERL is an element of the U.S. Army Engineer Research and Development Center (ERDC), U.S. Army Corps of Engineers. The Commander and Executive Director of ERDC is COL James R. Rowan, and the Director of ERDC is Dr. James R. Houston. 


\section{Introduction}

\section{Background}

In accordance with the Endangered Species Act (ESA), the Army is required to protect and manage threatened and endangered species (TES) that occur on property under its stewardship. Of the 1,823 listed threatened and endangered species (USFWS 2004), 205 occur on, or adjacent to, 121 Army installations (Rubinoff et al. 2004). Consequently, TES represent a significant conservation and compliance challenge for the Army, posing numerous potential conflicts with mission requirements.

Army implementation of ESA requirements is outlined in Army Regulation (AR) 200-3 Natural Resources-Land, Forest and Wildlife Management (U.S. Army 1995). Recognizing that the key to a successful balance between mission requirements and conservation of listed species is long-term planning and effective TES management, AR 200-3 requires installations to develop an Endangered Species Management Plan (ESMP) for all listed (i.e., threatened or endangered) or proposed species. AR 200-3 stipulates that ESMPs must identify the TES current installation population size and set installation population goals. ESMPs also must identify the species' current and potential habitat (i.e., that made suitable through management) on the installation. Via informal consultation, the Fish and Wildlife Service or National Marine Fisheries Service provides input during the development of the ESMP.

Although seemingly straightforward, development of ESMPs can represent a significant challenge, especially when the biology of TES is poorly understood or little installation-specific information is available. In a general sense, much of ESMP development falls under the scope of species-habitat modeling. This report will assist TES managers on Army installations in defining the most effective approaches for species-habitat modeling on Army installations. The types of quantitative methods that fall under the heading of species-habitat modeling are quite varied, both in terms of the complexity of the underlying models and the quantity of data deeded to parameterize them. For example, a TES manager may need to: (1) identify the occurrence of a certain species on the installation, (2) provide a map of locations where species are likely to occur, (3) estimate how many individuals use installation habitat, (4) calculate the number of individuals that an installation can reasonably expect to conserve over a long time period (i.e., the carrying capacity), (5) estimate the 
probability a population will not go extinct over a given timeframe, or (6) address some other related question. Widely varying questions in TES management demand a variety of scientific tools and approaches to ensure that the best information is available for decision-making. This report can assist in the selection and refinement of the best approach to answer such questions. Although most managers utilize species-habitat modeling to estimate TES abundance or distribution in some way or another, there is misgiving about the accuracy of model output (O'Connor 2002). Since the value of models should be assessed before they are applied, this report also addresses accuracy analysis and uncertainty.

\section{Objective}

The Objective of this research was to provide an overview of species-habitat modeling approaches, including recent recommendations and criticisms of model shortcomings. Rather than provide an exhaustive treatment of species-habitat modeling, this report provides enough information so an installation could hire or supervise an expert to conduct appropriate modeling, and anticipate and avoid common pitfalls and errors associated with current approaches.

The task of estimating TES population goals and/or viability estimates on Army installations is closely related to understanding, delineating, and characterizing habitat. Current and future TES population abundance and viability can be understood only through knowledge of habitat choice, carrying capacity, and fitness value to the species of interest. This report focuses strongly on habitat-based modeling for the purposes of developing TES population goals on installations.

\section{Approach}

Species-habitat modeling approaches were organized into a hierarchical structure having three general classes, based on data requirements, effort, expense, technical difficulty, application uses, and output characteristics. This report begins with a brief introduction to this organizational structure. Following is a review of several issues that are important regardless of what particular modeling question or approach is required. Next, this report contains a summary of the three general classes of modeling approaches along with their most common applications, strengths, and weaknesses. Next, is a discussion of the specific issues related to species-habitat modeling, starting with important considerations for modeling habitat, then moving into the issues of quantifying species' response to habitat (i.e., behavior, reproduction), and finally, the statistical approaches for modeling the relationship between habitat and species' response. This report does not provide 
detailed step-by-step instruction for methods, such as point counts or classification and regression tree (CART) analysis, which could fill volumes. Instead, when a recommended approach requires careful consideration of many details, references to additional sources of appropriate information are included. Lastly, there are two sections dealing with error, uncertainty, and validation procedures.

\section{Mode of Technology Transfer}

This report will be made accessible through the World Wide Web (WWW) at URL: http://www.cecer.army.mil 


\section{Introduction to Three General Classes of Species-Habitat Modeling}

Using a hierarchical structure for organizing species-habitat modeling approaches, modeling approaches are grouped into three classes, based on data requirements, effort, expense, technical difficulty, application uses, and output characteristics. Each succeeding class includes many or all of the tools and approaches of the preceding classes. TES managers can examine the descriptions of the three classes and identify the modeling approaches most appropriate for any particular need. One or more sections of this report will be useful for each applied modeling requirement, depending on what class of modeling is sought.

\section{Class I - Predicting Species Presence and Absence}

With respect to a hypothetical area of habitat, Class I models address the question: "Can the species of conservation concern exist here?" Class I approaches include surveys for the presence of a species, evaluation of what components of habitat are associated with species occurrence, and mapping of potential species presence or absence based on habitat characteristics. Class I approaches are suitable when minimal knowledge and data are available and/or needed regarding species habitat use. A Class I approach is suitable for asking "In any given habitat, what is the chance of finding a particular focal species?" TES managers may wish to know whether a species occurs on the installation, or may need to map potential or actual distributions in anticipation of future conservation concerns. Underlying these relatively simple requirements are three assumptions: (1) species are linked to their habitats strongly enough that presence can be predicted by habitat characteristics,

(2) habitats can be identified and characterized, and (3) the species is detectable (Dreisbach et al. 2002).

\section{Class II - Predicting Species Abundance and Quantitative Response to Habitat}

With respect to a hypothetical area of habitat, Class II models address the question: "How many can exist here?" Class II approaches are used when the variation of TES abundance across different habitat areas is of interest. Class II approaches 
examine the relationship between environmental variables and counts of individuals, or abundance or density estimates of species. Class II approaches include estimates of installation carrying capacity that are based on differential densities across habitats. Class II approaches include models of population change through time. This can be accomplished using data from repeated censuses to conduct a count-based population viability assessment (see Count-based PVA, page 31).

\section{Class III - Quantifying Species Demographics in Habitat}

With respect to a hypothetical area of habitat, Class III models address the question: "How many can persist here, for how long, as conditions change?" Class III approaches focus on the measurement of demographic parameters as components of fitness, such as survivorship, growth, and fecundity in different habitats and/or under different management scenarios. Class III approaches allow TES managers to predict the probability of population extinction with actual or theoretical habitat configurations. They also allow analysis of underlying demographic mechanisms of population change and long-term population trends. A range of possible future population sizes can be estimated through simulation modeling, and then used to define a reasonable goal for TES conservation. 


\section{Initial Modeling Considerations}

Several considerations are important for any species-habitat model, regardless of the classes adopted in this report or the specific methodology chosen. Every modeling effort is plagued by a trade-off between generality and accuracy for a particular location. General, widely applicable models are often simpler than location-specific models, and may be limited to broad patterns or theoretical constructs (van Horne 2002). Location-specific models do not consider variation throughout a species' range; they focus directly on critical, local factors thought to be relevant in a specific place during the immediate time frame. For example, in the northern part of their range, Belted Kingfishers (Megaceryle alcyon) are limited to areas having ice-free rivers (Kelly and van Horne 1997). However, this is likely not an important constraint in southern portions of their range. Location-specific models are recommended for species management on installation lands, especially when legally binding decisions will be based on the results. Maximum predictive ability requires custom-built models generated and tested with local data. Such models should not be expected to predict well in different places at different times. They are focused on a specific, immediate requirement. Too much natural spatial and temporal variability exists to expect anything more. Installation personnel will achieve maximum success by focusing on local data collection, local observation of species, and small, focused models for specific uses. It may not be effective to survey existing (outside) modeling efforts in the hope that a completed general species model can be found. Even if another model exists, it may not fit well enough to local conditions to make accurate predictions. Models that have been developed via local parameterization, (e.g., using RAMAS software, Applied Biomathematics), however, are worthy of consideration and comparison during the development of a new model. In some cases, specific local circumstances are highly relevant, yet are not included in packaged software. Installations are encouraged to maintain control over the scoping and development of models that focus on a specific time, place, and management requirement. In most cases, this calls for model development over short time periods by in-house or closely aligned personnel (Starfield 1997). Such an approach may free enough time and money to complete model testing and evaluation and to estimate confidence limits for the model output.

Due to the highly variable nature of ecological systems, most of the common statistical approaches to species-habitat modeling are unable to ascertain cause-andeffect relationships. Controlled, manipulative experiments can test only one or a few variables at any one time, and are thus very limited in their scope. Van Horne 
(2002) advises using a mixture of approaches. For example, correlative or descriptive approaches may define broad patterns of habitat use, but experiments at a particular location can uncover the causative importance of variables such as habitat structure or food supply. Two additional resources on modeling causation are Pearl (2000) and Shipley (2000). 


\section{An Overview of Logical Approaches to Species-Habitat Modeling}

\section{Correlative Approaches - Descriptions of Locations}

Correlative approaches to modeling species-habitat relationships are traditionally executed with multivariate statistical analyses, such as principle components analysis or discriminant function analysis, to reveal characteristics of the environment that best explain species-related parameters. Conceptually, the researcher attempts to describe a subset of the n-dimensional axes that determine the species' niche, based on Hutchinson's (1957) niche concept (James 1971). For example, Shaw and Atkinson (1990) identified the relationship between species presence and slope, aspect, geology, and land cover to map the distribution of Golden-cheeked Warblers (Dendroica chrysoparia) and Black-capped Vireos (Vireo atricapillus) in Texas. Philosophically, correlative approaches to modeling species-habitat relationships should reveal species response, with minimal chance of imparting researcher bias. Practically, this means that all potentially important environmental variables must be measured across the full range of potential values. Correlative approaches can be applied to data collected at random points, stratified random points, or points used to compare "used" sites with random or "unused" sites.

Correlative approaches suffer from several weaknesses (van Horne 2002). It is difficult to observe and measure habitat through the point of view of the organism studied. The variables included in correlative analyses tend to be aspects of the environment that are easily measured. Traditional statistical procedures limit the shape of the relationship to choices that rarely reflect the theorized shape of species responses. Yet another challenge is the difference in species' response to the environment at different spatial and temporal scales. Therefore, it is essential to match the scale of the question with the scale of data collection and modeling. A final problem is the fact that correlations are not the same as causal factors. Causal factors may vary, leading to disintegration of the correlative relationship. Most of these issues will be discussed in more depth below. In addition to these weaknesses, O'Connor (2002) states that "limitations of current concepts are marked and aggravated by generally poor implementation of the available approaches." He advocates a shift to a new paradigm, a habitat constraint paradigm, in which differences in species abundance through space are conceptualized based on the status of 
limiting factors, which change not only in their availability, but also in relative importance, from location to location. (The correlation between limiting factors and species abundance is not modeled under O'Connor's proposed paradigm; see An Alternative Paradigm - Modeling Constraints with CART, page 50, for an example of methods that support this approach.)

\section{Resource Selection Approaches - Comparisons of Habitat Use by Animals}

Resource selection studies compare estimated or known habitat availability with measured habitat use by the species in question. Habitat types must be defined beforehand (Garshelis 2000), so that estimates of availability can be made in the field (through point counts or plot methods) or documented habitat can be measured from maps or remotely sensed images (Thomas and Taylor 1990). Methods for measuring species response vary widely. Sometimes, individual animals are radio-tracked. Alternatively, the entire population can be sampled through sign or sightings, without measuring the patterns of individuals. In either case, the proportion of habitat used is compared to the proportion of habitat available, for each habitat type category. Within this approach, it is important to guard against pseudoreplication from non-independence of observations (Hurlbert 1984), especially when compiling location data points for the same individual (Thomas and Taylor 1990). One of the weaknesses of use-availability studies is the inherent assumption that if habitat is desirable, it should always be used in increasing proportion with its availability. In fact, an asymptotic relationship could exist between habitat availability and use, even with the highest quality habitat. The spatial distribution of habitats and relationships between multiple habitats could be more important than simple choices between different habitat types (see Garshelis 2000 for an excellent discussion). Resource selection studies have been used to indicate long-term habitat requirements, model the effects of habitat change, evaluate output from other models, estimate population size, and estimate parameters in foraging models (Manly et al. 2002).

\section{Knowledge-based Approaches}

Knowledge-based models, or "expert systems," are built on the opinions of experts. Often, population viability analysis or TES recovery team workshops build knowledge-based models. In knowledge-based approaches, relationships between habitat types and species' fitness (e.g., survival and reproduction) are often described through a combination of expert opinion/experience and available data sets. Using this approach it is possible to delineate any shape to a relationship, across any 
range of variables (van Horne 2002). Since existing models are likely to be general models, based on a consensus of experts studying a range of situations, they are unlikely to be highly accurate in predicting species response to any particular location (as discussed above), unless created specifically for local purposes. In addition, it is important to evaluate whether such models add any value beyond that offered by expert human opinion alone. For example, Meesters et al. (1998) used a combination of expert opinion and case history data to describe coral reef condition under the influence of seven causative factors. Expert knowledge was captured and organized for a total of 2,187 combinations of causative factors and response variables. The relationships were evaluated on an iterative basis and organized in a manner useful for conservation management. However, as O'Connor warns, this type of model "does not predict in the usual scientific sense, but rather encapsulates a wealth of real-world experience" (O'Connor 2000). 


\section{Quantification and/or Description of Habitat}

\section{Classification of Habitat Into Types}

Austin (2002) reviews the importance of ecological theory and survey design for predicting species distributions. How is habitat discriminated and named? This report uses the term habitat in reference to habitat type, defined as "an area, delineated by a biologist, that has consistent abiotic and biotic attributes such as dominant or subdominant vegetation" (Jones 1986). Ecological studies over time have demonstrated that plant communities are not homogenous, co-evolved, and discrete entities. Instead, plant species respond to environmental variables in an independent fashion. Plant communities, as such, occur when combinations of environmental conditions occur frequently enough that the resulting species combinations warrant recognition as entities.

Despite ecological theory and empirical results, resource selection studies require the a priori definition of discrete habitat units (Garshelis 2000). Such studies require estimation of baseline habitat availability and therefore must begin with definitions of the different habitat types to be included. For example, a study of escape cover use by California Quail (Callipepla californica) began with the delineation of six cover types: pasture, disturbed cover, farmstead, riparian, shrubland, and field border (Stinnet and Klebenow 1986). Traditional analyses for use-availability studies are weak since results are strongly affected by how many habitat types are defined. As the number of categories increases, sample sizes for each type are reduced, lowering the power of the study. Furthermore, since all proportions must add to 1, differing numbers of habitat types strongly affect the resulting proportions of all habitat types, and affect the resulting statistical comparisons (Aebischer et al. 1993). Similarly, the decision to include or exclude "doubtful" habitats, such as common types that are not used, is problematic. These drawbacks have been reduced or eliminated by alternative statistical procedures (Alldredge and Ratti 1986) and will be discussed further in Resource Selection Studies, page 42.

Correlational studies intend for the data itself to define important habitat characteristics. A logical extension is that a priori categorization of habitat types would be unnecessary and misleading. However, separate a priori habitat types may surface 
in the design and interpretation of such studies, if the study is limited to a subset of habitat types. For example, Young and Hutto (2002) explain that "to reduce the confounding effects of very different cover types, some of which we know this species would not occur in, we modeled the habitat associations of the Swainson's Thrush (Catharus ustulatus) within the subset of conifer forest types." For Class I-related objectives, especially on legally protected species, this would not be appropriate. Although such a decision was acceptable for Young and Hutto's purpose, most Class I efforts conducted on installations should ensure that such limiting assumptions are not made.

\section{Assessing Degree of Habitat Suitability or Quality}

In 1937, Aldo Leopold remarked that the task of habitat assessment constituted one of the more significant challenges for wildlife managers (Leopold 1937). It is widely recognized that the process of defining habitat quality is fraught with uncertainty. Several non-traditional methods have been applied in an attempt to more closely formalize the process by which a human would judge habitat suitability or quality. This report considers two approaches: fuzzy set theory and pattern recognition using Bayesian techniques, as applied to the question of habitat assessment. These approaches warrant consideration for habitat quality evaluation.

Hill and Binford (2002) argue that the underlying theory and logic of species-habitat relationships, such as habitat classification or habitat quality assessment, require non-discrete categories for predictive modeling. Non-discrete (ambiguous) categorization is based on fuzzy set theory rather than classical set theory. Fuzzy set theory has been applied to habitat modeling only relatively recently. How does fuzzy set theory differ from classical set theory? A classical set depends on discrete, "crisp" categories. Membership in a category is absolute; an element either belongs to the category or it does not, so it can be captured with a "yes/no" dichotomy. There is a crisp threshold that defines the upper and lower limits of the category. Classical sets can be subjected to probabilistic mathematics. According to the discussion of Hill and Binford (2002), probability theory works in the following manner: if managers need to know the probability of a particular organism occurring at a particular point in space, a study would be conducted to monitor that point in space over a very long period of time, and eventually, the data would allow managers to calculate the mathematical probability of the organism's occurrence at that point. Uncertainty in prediction would come from the state of information of the observer, in light of random stochasticity and degree of knowledge, regarding the occurrence of the organism through time. Thus, any application of the results to predicting occurrence in a different location would assume that differences in occurrence could only result from stochastic processes, something that is biologically unrealistic. Despite 
the weakness of this approach, such probabilistic theory provides the basis for most inferential statistics (Hill and Binford 2002).

Fuzzy set, or ambiguous, categories are defined based on similarity to a theoretical, absolute state of belonging to a category. Membership in a category is often defined in terms of a gradient. The gradients in degree of membership are based on the degree of similarity to an absolute state, and thus, are captured with a graded, "0 to 1 scale" valuation. Uncertainty about membership in the category comes from the actual gradation in the degree to which the statement "This object belongs to class $\mathrm{X}$ " is literally true. If either the upper or lower bounds of a category boundary are ambiguous, then the category must be considered ambiguous. The theory of species' niche underlies the concept of habitat quality. Thus, membership in the category of "suitable habitat" would relate to the similarity of the habitat element to the niche. Or, alternatively, as long as species respond, in different degrees, to gradients in the environment, and there exists a (theoretical) optimal environmental condition (based on expert knowledge at any given time) for the species, the underlying logic of habitat evaluation is one of fuzzy set theory, including ambiguous categories and fuzzy set mathematical functions (Hill and Binford 2002).

The use of discrete boundaries between categories of habitat suitability can be influential in modeling applications. Consider the influence of slope on a hypothetical plant. If a slope of 8 percent is determined to be the boundary between high quality and moderate quality habitat, does it make sense for plots with slope of 7 percent to be considered absolutely different from plots with slope of 8 percent? Using fuzzy set logic, a more continuous range of quality can be represented, and it can also include uncertainties in measurement of slope (Baja et al. 2002).

Pattern recognition advocates the use of probability theory in combination with Bayesian analysis to formalize an approach to habitat assessment that attempts to mimic the human thought process. Pattern recognition allows model developers to use available data to calculate prior probabilities and conditional probabilities in the central formulation of the model. For example, Sweeney and Dijak (1985) used observed probabilities (from earlier field studies) that forest stands of various types supported Ovenbirds (Seirus aurocapillus). Nine stands of forest type 79 supported Ovenbirds while 8 stands did not. The conditional probability for forest stand 79 to contain Ovenbirds was 0.19 and the conditional probability that forest stand 79 would not contain Ovenbirds was 0.26. This process was conducted for five variables (included variables were selected based on an earlier study analyzed through discriminant function analysis). The prior probabilities were simply the overall numbers of stands of all types that contained or did not contain Ovenbirds during the field study (Sweeney and Dijak 1985). An equation based on Bayes' Theorem then incorporated these probabilities into one posterior (resulting) probability that 
the forest stand is suitable Ovenbird habitat. In this example, "suitability" was defined as having a posterior probability greater than 0.5 .

\section{Spatially Explicit Habitat Evaluation}

Living organisms are not randomly or uniformly distributed throughout their geographic range. Geomorphologic processes and variation in energy input lead to spatial structure, most commonly patches or gradients (Legendre and Fortin 1989). It is important to consider the spatial arrangement of habitat patches when sampling in the field or modeling available habitat, current population numbers, carrying capacity, or population goals for an installation. Schulz and Joyce (1992) estimated numbers of marten (Martes americana) home ranges using hypothetical spatially explicit habitat models (that included differences through space), and spatially neutral models (that did not include differences through space). Numbers of home ranges were determined by summing up the total number of sufficient home ranges in the spatially explicit models. In the spatially neutral model, numbers of home ranges were determined by dividing the total area of habitat by home range size. Spatially neutral models led to higher numbers of estimated home ranges. The discrepancy was greatest for the landscape with the least amount of good quality habitat. They concluded that without spatially explicit information, small, separated patches of habitat were interpreted to be useful habitat, which is biologically incorrect (Schulz and Joyce 1992). Based on this result, a spatially explicit approach for Class II and III studies is recommended. Otherwise, population carrying capacity on an installation may be overestimated.

\section{Scale of Habitat Measurement}

The scale of habitat definition and measurement is critical (Wiens 1989). Response to microhabitat and macrohabitat may or may not be similar. An organism may appear to select for a particular habitat type (at the macrohabitat scale), yet actually be seeking out specific sites or characteristics (at the microhabitat scale) that happen to occur more commonly in that habitat (Garshelis 2000). On the other hand, if a study focuses on choices within an animal's home range, such as a telemetry resource selection study (see Resource Selection Studies, page 42), the results cannot describe the importance of the location of that home range within a larger context (Smallwood 2002). Biologists commonly assume that data gathered from a habitat patch applies to all individuals within that patch. Alternatively, spatially aggregated individuals are often treated as individual observations, which may not be the case. The critical problem is that there are no natural (a priori) spatial units; divisions of habitat are a function of human observation. Thus, statistical analyses 
are highly dependent on how habitat is zoned or aggregated, and results can vary widely under different decisions (Henebry and Merchant 2002). In some cases, evidence of habitat quality is contradictory as scale varies. For example, Dooley and Bowers (1998) found that habitat fragmentation reduced population size, but increased reproduction within individual habitat patches. It is important for managers to be very clear about what question they wish to have answered by the model and by the supporting field studies. If management actions or land use questions are important requirements, the appropriate scale for those human-related activities must influence the choice of scale for research and modeling employed so the relevant species response can be identified.

Such difficulties can be minimized by adequate information suggesting ecologically meaningful ways to combine or separate habitat into categories. Pedlar et al. (1997) developed two models to describe variation in raccoon density; one at the macrohabitat scale and one at the micro-habitat scale. The two models were then combined to form a more complete model relating raccoon (Procyon lotor) density to habitat at both scales.

In Class I type efforts, TES managers usually will not have enough information to predict the most appropriate spatial scale for habitat aggregation. If a few individuals of the species have been located, managers may consider a preliminary study to evaluate individual movement behavior and spatial aspects of habitat use and habitat distribution before designing a large survey to map species occurrences. Even such preliminary work should be considered at nested scales to the extent possible. Such preliminary data, combined with clear objectives for research at Class I, can suggest the most appropriate scale or scales for habitat delineation, data collection, and analysis. Additional guidelines and tutorials on these issues can be found in King (1991), King et al. (1991), and Rastetter et al. (1992).

Choosing an appropriate scale becomes even more critical for Class II and III studies. For example, Laymon and Reid (1986) found that a 16-ha cell size was adequate for predicting Northern Spotted Owl (Strix occidentalis caurina) presence and absence, but was not appropriate for predicting habitat preferences as measured by frequency of use. A cell size of 4 ha provided enough detail that high-use habitat was more consistently identified, although habitat data at this resolution did not fully explain Northern Spotted Owl behavior. Similarly, Wiens et al. (1987) found that measured relationships between bird species presence, density, and habitat characteristics varied with virtually every change in spatial scale at which the system was studied. Following Wiens et al. (1987), it is suggested that: 
1. Correlations of species counts with habitat features (Class II) should include the measurement of variation between plots, with plots placed across a wide range of environmental gradients,

2. Research at Classes II or III be conducted over more than 1 year, so consistency in habitat selection can be assessed and temporal stochasticity can be considered,

3. Detailed behavioral studies should be conducted to the extent possible, so the meaning of habitat associations can be assessed.

\section{Selecting and Sampling Variables}

\section{Point and Plot Sampling}

Alldredge et al. (1998) lists assumptions that should be considered in studies that correlate habitat variables with organism response. First, it is assumed that the locations available to the organism have been accurately identified. For example, if some locations are not accessible due to barriers or distance limitations, they should not be included in a habitat study. Second, it is assumed that the study accurately identifies used areas and unused areas. Third, it is assumed that the environmental variables measured influence habitat selection, and that these variables do not vary in their distribution during the study timeframe.

Sampling of habitat for a correlative study begins with a hypothesis identifying the major limiting factors in the environment. Sample design should encompass gradients of all primary environmental controls in order to sample the complete range of possible values. It is imperative to include all conditions and the full potential range of values if the results will be used to make predictions outside of the study area boundaries, for example, to create a map of species occurrence for the entire installation.

Austin's (2002) review of environmental gradients in ecological modeling concludes that even for individual species, relevant environmental gradients and predictor variables vary from region to region. Successful modeling relies on capturing the essential combinations of biotic and abiotic conditions through a rigorous survey design in the location of interest.

Gradsect sampling (Austin and Heyligers 1989, 1991) is a gradient-directed form of sampling that aims to provide a description of the full range of variation over an area while minimizing survey costs. Gradsects are simply transects arranged to contain the strongest environmental gradients in an area. The technique maximizes variation between plots and has been shown to capture more information about habitat than random transects of similar length (Gillison and Brewer 1985). 
However, it is a non-random technique, and is intended to characterize (survey) the landscape for variation, not to obtain unbiased estimates of mean values for the landscape (Austin 2002). This type of survey would be useful for studies at Class I to identify rare species presence or absence, or at Class II to estimate relative density across habitat types.

Boundary conditions are found on the edges of a species range, and describe the states in which habitat values are consistent with species occurrence to the states in which habitat values are not consistent with species occurrence. Boundary conditions and environmental gradients are perceived by organisms, and will affect species response to habitat, especially as the variable becomes limiting. For example, the Venus flytrap (Dionaea muscipula), a Federal Species of Concern found on several southeastern Army installations, requires a soil pH range of 3.9 to 4.5 (Roberts and Oosting 1958). These values for the environmental variable " $\mathrm{pH}$ " are boundary conditions. A study design incorporating the maximal range of values for habitat characteristics allows the determination of boundary conditions for important variables (van Horne 2002). This approach also makes it much easier to determine if a related model can be extended for use in a new location. Such information reduces the risk of model application in an inappropriate environment (van Horne 2002) and assists in mapping the results.

\section{Remotely Sensed Data as Habitat Variables}

Availability, comprehensive coverage and interest in landscape-level phenomenon have all contributed to the popularity of remote sensed data in habitat modeling. Remotely sensed data support the examination of landscapes (see Landscape Metrics as Habitat Variables, page 19), which is critical for investigating species-habitat relationships of TES that are highly mobile or have large home ranges. Data across large extents of land provide a means to map natural heterogeneity, regardless of the specific application. Clark et al. (1993) used forest cover and stand maps from the U.S. Forest Service to develop a map of black bear (Ursus americanus) habitat with high potential for use. Condition classes (phases of forestry production such as mature saw timber, pole timber, etc.) and forest type (pine, hardwoods, etc.), roads, streams and elevation were processed into new geographic categories using a geographic information system. These habitat variables were then used to predict the probability of habitat use using a technique based on the Mahalanobis distance statistic.

How useful is remote sensed data? Can it substitute for data gathered in the field? One study from the California Mojave Desert reported that digital elevation models and derived variables such as slope could substitute for fine-scale field observations when remote sensed imagery resolution was approximately 5 ha. The same study 
found mixed results when trying to compare landform categories defined from remote sensed imagery and from field observations, in part due to observer error in the field (Thomas et al. 2002).

Corsi et al. (2000) conducted a literature review of 82 papers discussing species distribution models that utilized geographic information and GIS tools. They include issues related to remote sensed data in their review. There are two types of error inherent to remotely sensed images: geometric and radiometric. Geometric error results in a point on the image occurring in the wrong position relative to other points in the image. Some causes of this error include movement in the sensing platform, distortion caused by terrain and the earth's curvature, the earth's rotational skew, etc. This type of error is routinely corrected during pre-processing. Radiometric error leads to differential distortion among electromagnetic bands. It is caused by imperfections in equipment and differential scattering of different wavelengths for various reasons, such as irradiance variation and terrain topography. For more information on these types of error, see Richards (1986) and Colwell (1983). For details about using remote sensed data in habitat modeling, see Corsi et al. (2000), Tso and Mather (2001), and Skidmore (2002).

Assessment of error in remotely sensed data estimates the proportion of correctly mapped pixels in the image, a process that requires independent sampling of ground conditions for comparison. Congalton (1988) explored optimal sampling design for error assessment by simulating five sampling schemes (simple random, stratified random, cluster, systematic, and stratified systematic unaligned [areaweighted] sampling patterns) with different sample sizes across three different image types (forest, rangeland, and grassland). He concluded that systematic sampling and stratified systematic unaligned sampling can overestimate parameters. He concluded that cluster sampling can be used, provided a maximum of 10 sample pixels per cluster are selected, and that stratified random sampling can be used when small areas are needed in the sampling scheme. He also found that simple random sampling worked well in all situations.

The number of samples must be traded off with the area covered in each sample, based on limited time and money available for error assessment work. Curran and Williamson (1986) recommend that in a highly variable habitat type, such as a rainforest, many small-area samples are best, while in more homogenous habitat types, fewer, larger sample sites are more effective. Toll (1984) specifies that heterogeneous image classes (i.e., forest, residential areas) are more accurately mapped at a resolution of 80 meters when compared to a resolution of 30 meters. The converse is true for image classes that are more homogenous, such as agricultural land or rangeland (Toll 1984). 
It is important to consider using fuzzy set theory when selecting or manipulating remotely sensed data, GIS applications, and the use of GIS data in modeling efforts. Fuzzy logic has been shown to be superior at representing the gradual transition of land characteristics during land evaluation processes. For example, if an important boundary condition exists at $10 \mathrm{~km}$ from forest edge, Boolean logic would dictate that the locations at $9.5 \mathrm{~km}$ and $10.5 \mathrm{~km}$ be treated as totally separate conditions. With fuzzy logic, the difference between the two locations could be handled in a gradual manner that more closely resembles many ecological boundaries. The use of fuzzy logic promises to reduce the level of information loss as compared to the use of Boolean logic for retrieval and overlay of GIS data (Zadeh 1994). When appropriate, fuzzy logic should be used to process data within GIS.

Any error in the original remote sensed data is preserved, and sometimes increased, when layers are combined, something that is inherent to most species modeling efforts. Estimating the accuracy of final model output is called error propagation analysis. The error within each layer must be measured. The interdependence of data across layers, the interdependence of errors across map layers, and errors in any rules used to process (i.e., categorize) mapped data all affect the accumulated error of final spatial output.

\section{Landscape Metrics as Habitat Variables}

Landscape metrics describe heterogeneity across distances of land at a greater extent than most traditional field data collection. Data often originate with remote sensing, either airplane photography or satellite imagery. Landscape metrics are potentially useful any time heterogeneity through space is important. For example, species that are highly mobile or have large home ranges (e.g., large predators, bats, and migratory herbivores) sample their environment over large extents (e.g., the endangered lesser long-nosed bat [Leptonycteris curasoae] may forage nightly across distances of 20 to 30 miles from day roosts; USFWS 1997). In these cases landscape metrics should be examined as relevant habitat variables.

In addition, it is often important to understand the context within which a survey point or habitat patch occurs. Variables based on landscape metrics provide a quantified description of the surrounding land. Landscape configuration can influence organism movement, home range, and habitat choices, as well as survival and reproduction.

There are many different landscape metrics. A landscape is defined here as a mosaic of habitat patches in which a patch of interest is embedded (as articulated by Dunning et al. 1995). Patch size, patch type, and patch context (spatial arrangement, diversity) are major categories of metrics often used in species management 
modeling. Most metrics are not independent, and all are affected by resolution (see below) and boundary effects (see Point and Plot Sampling, page 16). For more information, see Riitters et al. (1995).

Most species-habitat models that incorporate landscape metrics will include a measure of patch size and some basic measure of distance between patches, concepts taken from island biogeographic theory. Walker et al. (2003) found that a simple model using patch size and distance between patches was not adequate to predict species distribution in the mountain vizcacha (Lagidum viscacia), a rodent. The reasons for this result were that (1) vizcacha habitat patches varied in habitat quality independent of patch size, and (2) features in the habitat matrix between patches (e.g., rivers) affected the ability of the species to move between patches (Walker et al. 2003). Moilanen and Hanski (1998) came to a similar conclusion when trying to predict the distribution patterns of the Glanville fritillary butterfly (Melitaea cinxia). Their most complex model included habitat classes derived from 44 categories of land cover types from 25-m resolution Landsat imagery. Habitat quality was influenced by perimeter type, presence of grazing, density of flowering plants, and abundance of larval food species. The median patch size was $300-\mathrm{m}^{2}$, less than half the area of each pixel of Landsat data. This resolution clearly did not adequately characterize the matrix characteristics most important to the species. For some butterfly and beetle species, isolated patches surrounded by inhospitable matrix qualities are much less likely to be occupied than patches that are equally isolated, but surrounded by a more hospitable matrix (Ricketts 2001).

In another study, patch size and a measure of isolation explained the distribution of the Florida scrub lizard (Sceloporus woodi) across a naturally fragmented environment. Aerial color photos with 2-m resolution were used. The measure of isolation included distance between patches, as well as matrix permeability and the area of occupied neighboring patches. However, the model did not perform well in predicting the distribution of a more widely distributed lizard, even though the two species are similar in body size, food habits, and habitat requirements. The more common species has greater dispersal abilities and may be more tolerant of dense vegetation (Hokit et al. 1999).

A much more complex model was used to predict the distribution and abundance of 32 avian species across 57 cottonwood (Populus deltoides Bartr. ex Marsh.)patches, ranging in size from 0.4 ha to 205 ha (Saab 1999). Here, landscape patterns were the most important variables predicting occurrence of many bird species. The habitat variables utilized were: woody plant stem density, canopy cover, and ground cover. Patch-level variables included: patch size, perimeter to area ratio of each patch, length of patch, width of patch, edge contrast, and core area. Matrix variables included: percent of landscape the patch represented, Simpson's index of di- 
versity, relative patch richness (including 10 nearby patches), Simpson's evenness index, and an interspersion index. Landscape structure was captured with distance to contiguous riverine forest, distance to nearest neighbor patch, and landscape edge contrast. These variables were processed using principle components analysis (see Correlative Approaches, page 37) since many of them were correlated. Multiple linear regression was used to evaluate the effect of the resulting variables on bird species occurrence and abundance. The most influential variable overall was a measure of landscape composition (habitat types). Landscape heterogeneity was also important, as was patch size and edge characteristics (Saab 1999).

The resolution (pixel size) used to calculate landscape metrics is an important consideration. Trani (2002) calculated four measures of spatial heterogeneity, eight measures of fragmentation, and two measures of edge for 22 forested landscapes, each at 14 different resolutions, ranging from $30 \mathrm{~m}$ to $420 \mathrm{~m}$. Her results, below, suggest that some landscape metrics are better than others at maintaining values close to their original, most-detailed landscape value (in this case, $30 \mathrm{~m}$ ) as coarser versions of the landscapes are generated.

When measuring spatial heterogeneity, the landscape evenness index (as defined by Romme 1982) and the Simpson Index (as defined by Pielou 1977) change value less dramatically at coarse scales (pixel sizes above $270 \mathrm{~m}$ ) than the interspersion index (as defined by Eastman 1997) and the binary comparison matrix (as defined by Murphy 1985). The first two indexes display a change in value of less than 10 percent when compared to the most detailed map of 30-m resolution. In contrast, the latter two indexes display a change in value of 600 to 800 percent (Trani 2002).

Fragmentation metrics lost information more dramatically following a decrease in grid size resolution in this order (from least to greatest): forest cover (as defined by Lauga and Joachim 1992), contiguity (as defined by LaGro 1991), number of patches (as defined by Trani 1996) (patch size [as defined by Dunn et al. 1991] and interpatch distance [as defined by Urban and Shugart 1986] displayed similar responses), forest interior (as defined by Dunn et al. 1991), fragmentation index II (mean distance to non-forest pixels; as defined by Ripple et al. 1991), and fragmentation index I (ratio between polygon count and pixel count; as defined by Monmonier 1982). Thus, if a study is limited to low-resolution spatial data, it may be best to utilize metrics such as forest cover or contiguity rather than either of the fragmentation indexes. The specific responses of some metrics depended upon the complexity of the original landscape or the presence of specific elements on the original landscape (Trani 2002).

The two edge metrics performed similarly. Both the total length of edge (as defined by Ranney et al. 1981) and the convexity (perimeter to area ratio; as defined by 
Berry 1991) displayed a change in value of 50 percent when the value from the 420 $\mathrm{m}$ landscape is compared to the value from the 30-m landscape. Both indexes lost information with each successive increase in pixel size (Trani 2002).

\section{Incorporation of Uncertainty in Habitat Measures}

Variables measured in the field and characterized by sample means include uncertainty around the mean, which is usually expressed as a standard deviation. Although the mean value is often input into models, the variation is often ignored. However, the variation captures both the sampling error and natural heterogeneity. Natural heterogeneity is comprised of temporal, spatial and individual variation (White 2000).

White (2000) argues that temporal and individual variation must be included in the basic model, and spatial variation should be as well, whenever the habitat is spatially structured. To assess the underlying natural variation in habitat measures, it is first necessary to remove sampling error. A procedure is provided by White (2000), citing Burnham et al (1987). Although White (2000) utilizes animal demographic data in his example, he adequately demonstrates that sampling error can be removed to reveal unbiased estimates of natural variation.

The use of confidence intervals explicitly includes variation in a habitat-based model, more accurately reflecting the range of possible, even likely outcomes, in model output. Bender et al. (1996) demonstrated two methods to estimate confidence intervals around habitat suitability index (HSI) model output: Monte Carlo and nonparametric bootstrapping.

In the Monte Carlo approach, the mean and standard deviation were used to generate 1,000 random values fitted to a normal distribution. This was repeated for each variable. Then values for each variable were randomly selected for input into 1,000 runs of the HSI model to produce 1,000 estimates of the final HSI score. Since the underlying distribution of variables may not be known, nonparametric bootstrapping was conducted as a second method of generating confidence intervals. One thousand random subsamples were generated from the original data samples, (with replacement) and then used to run 1,000 iterations of the HSI model, as above. Approximate 90 percent confidence intervals were created by eliminating extreme values from both ends of the final distribution of HSI scores (Bender et al. 1996).

Bootstrapped confidence intervals were always tighter than Monte Carlo confidence intervals due to small sample sizes and large variation. In this example, mean HSI scores ranging in value from 0.38 to 0.81 were not statistically different (Bender et 
al. 1996). Such an overlap indicated that varying HSI scores were not correlated with actual differences in habitat quality, and thus, a model validation study would not expect to report high estimates of HSI accuracy (Bender et al. 1996). However, it is useful to know that this apparent lack of accuracy could be entirely due to variability in input variables, not necessarily incorrect model relationships. Managers should include confidence intervals as an important aspect of the modeling exercise, whenever input variables consist of mean values with some inherent variation. For more details on these two methods of calculating confidence intervals, see Bender et al. (1996). 


\section{Quantification of Species Responses}

\section{Sampling Schemes}

There are two important aspects to sampling design. First, the sampling universe should be identified. The sampling universe defines the area in which samples will be chosen; it also defines the area in which results can be applied. For Army TES management, a sampling universe as large as possible is recommended. Cantonment and, in some cases, dudded live fire areas, likely will be excluded. But all likely or possible habitat areas, as well as nearby lands and plant communities that are not known to necessarily harbor the focal species should be included. The second aspect is development of the sampling scheme for examination of the sample universe. This second aspect requires many decisions that affect the choice of statistics, and the strength of results and interpretations. The following paragraphs summarize issues in point and plot sampling, territory mapping, and present cautions related to the use of density estimates. See Thompson (2002) for more details.

\section{Point Sampling}

Completely random and completely non-random, intentional designs are rarely used (Pendleton 1995). The most common sampling schemes for point sampling are stratified, cluster, or systematic sampling (for more details, see Cochran 1977). Stratified sampling and cluster sampling are hierarchical schemes. Stratification occurs when the largest area is divided into naturally-defined blocks, possibly based on vegetation type or a geomorphological feature, such as a drainage basin. Within each block, a certain number of sampling points are placed randomly. Stratified sampling is best used when you suspect large between-block variation and small within-block variation. Cluster design starts out with a random selection of large blocks of space, followed by intentional allocation of points within the selected blocks, usually to minimize travel time. Cluster design works well in the study of landscapes with small between-block variation and large within-block variation. More complex statistical analyses are often needed for these two hierarchical schemes compared to a simple random point design or a systematic design. Systematic sampling should always be started at a random point. Random sampling and systematic sampling are not recommended for rare species surveys, measuring characteristics of populations with clumped distributions, or measuring characteristics of populations with known temporal fluctuations. However, comprehensive 
mapping of a species' local distribution would benefit from systematic sampling (Pendleton 1995). For this purpose, selected points are often considered the center of a fixed circle, and sign of the focal organism is sought throughout the circle plot, as in most avian point count studies.

For very rare sessile species, or mobile species dependent upon a specific, very limited resource, such as a specialized shelter type, sampling units can be located purposefully at known places of species occurrence or resource occurrence. For example, van Manen et al (2002) quantified habitat conditions at all known butternut tree (Juglans cinerea L.) locations in the Great Smokey Mountains National Park to develop a predictive model for use in pinpointing further survey efforts. Projects that are categorized as Class I that are fortunate enough to possess some limited occurrence data should utilize this methodology as an initial step toward developing species-habitat information. This approach can be used to develop a correlative study or a resource selection study. This approach can be combined with expert opinion regarding habitat requirements and habitat conditions. Field results as well as species expert opinion can be used to identify locations of potential species occurrence.

Point sampling is adequate for surveys that are categorized as Class I. Since it is much less time consuming than territory mapping or radio-tracking individuals, point sampling is recommended for initial distribution surveys at Class I. However, point sampling is not recommended for projects that are categorized as Classes II or III. Difficulty in detecting the focal organism can weaken the power and accuracy of point count methods. Sauer et al. (1994) reported more than 50 percent of all birds are missed at any point during avian point counts. Estimation of detection probabilities using variable circle plots or mark-recapture studies, especially across different habitat types, allows for the adjustment of counts. A further reference on how to incorporate detection probabilities into field studies of this nature can be found in MacKenzie and Kendall (2002). Preliminary detection studies are very expensive and not practical for extensive surveys (Pendleton 1995). However, unless it is possible to calculate appropriate detection probabilities, and such probabilities are considered in the analysis, point counts are not considered rigorous tools for estimating abundance (Burnham 1981). The variability of detection can be reduced by rigorously standardizing the sampling protocol used. It is not known how effective such efforts are, but it is unrealistic to think that all factors affecting detection probabilities can be controlled (Pendleton 1995). Many additional issues deserve careful attention when designing point count census surveys (see Ralph et al. 1995 for many specific considerations for point count survey design). 


\section{Territory Mapping}

Territory mapping has been considered the standard against which less intensive census methods are compared (Cyr et al. 1995). Territory mapping can focus on home range estimation, core area estimation, and utilization distribution: Home range is defined as the area used during an individual's normal activities (Burt 1943). Core area is defined as the area used most frequently by an individual (Samuel et al. 1985). The utilization distribution (UD) describes the most detailed pattern of space use by individuals and can be used to derive core areas (Andreassen et al. 1993). The following techniques have been applied for calculating area use patterns: minimum convex polygon (MCP; Dalke and Sime 1938, Mohr 1947), cluster analysis (Kenward 1987), harmonic mean (Dixon and Chapman 1980), and the Kernel-UD (Worton 1989).

Carter et al. (1999) documented home range sizes and characteristics of bog turtles (Clemmys muhlenburgii) at three sites in Virginia. A total of 29 adults were radiotracked; 10 adults were tracked for both years of study. Two different procedures were used to estimate home range size: minimum convex polygon (MCP) and cluster analysis. Cluster analysis describes intensity of use by defining one or more core areas of use. MCP is the traditional method of choice, and offers the possibility of comparing new research results to older research results. MCP is known to be biased towards overestimation of area, whereas cluster analysis can underestimate area if the number of locations is relatively small (Kenward 1987). The home range sizes were similar for bog turtles of both sexes and for turtles at all three sites, regardless of estimation method used. The study was small in scale and duration, and thus offers limited value for making management recommendations. However, studies of this scale can be useful when conducted in the management area of concern, and can produce useful estimates of habitat carrying capacity and population estimates for planning purposes. It is recommended that home range studies utilize more than one estimation procedure, and interpret results explicitly in light of known ecological considerations to assist in application for management purposes.

Hansteen et al. (1997) reported a more detailed comparison in which 47 root voles (Microtus oeconomus) were radio-collared and relocated every 30 minutes over 1 to 3 days, with total sightings ranging from 40 to 144 for each individual animal. Three estimators were compared in this study: the MCP, the cluster, and the kernel. The kernel provided a nonparametric approach to home range analysis. It does not assume any underlying spatial distribution. It yields a smoothed bivariate distribution representing the animal's UD. This study also looked at the effect of increasing grid cell size on home range estimates. Results indicated that the kernel estimator was not affected, while polygon estimators (MCP and cluster analysis) resulted in larger home range estimates with increasing grid cell size (Hansteen et al. 1997). 
An organism may find itself in its home range in a particular habitat for a variety of reasons, and its subsequent choices may have little to do with habitat quality or optimal choices across a larger spatial area (Smallwood 2002). Any study of habitat choice by individuals should evaluate the demographic status and spatial relationship of those individuals to the entire population so the resulting conclusions about habitat quality and habitat use can be used at the scale needed (probably the scale of the whole installation).

Radio-tracking studies must be designed with an awareness of pseudoreplication (Hurlbert 1984) and its effects on the chosen statistical tests. For example, in the bog turtle study, the sampling interval was kept at 1 day or longer, which is known to be enough time for a turtle to move across its entire home range. Thus, the researchers were able to consider each observation as independent from the others (Carter et al. 1999). Hansteen et al. (1997) used Schoener's ratio (Schoener 1981, Swihart and Slade 1985, 1997) to assess autocorrelation, which in this case means pseudoreplication based on resighting intervals that are too small and are thus not independent. Swihart and Slade $(1985,1997)$ also provide a method for identifying the minimal time interval between non-autocorrelated intervals and for identifying activity rhythms that may be present in the data. In the vole study, Hansteen et al. (1997) found that the two shortest time intervals (30 and 60 minutes) created autocorrelated data, probably because the animals did not have time to move sufficient distances. They found higher degrees of autocorrelation in male movements compared to female movements.

There is an inherent tradeoff between risks of autocorrelation and sample size, in radio-tracking data. Increasing the frequency of resightings may increase autocorrelation, but also provides a larger sample size and more apparent statistical power in the study. Statistical power is weakened if there is strong spatial or temporal autocorrelation, due to a reduction in the "effective" sample size of the data set. Hansteen et al. (1997) evaluated the importance of sample size by subsampling a data set using resampling procedures. Their results indicated that all resampled data sets grossly underestimated home range and core area sizes, due to lowered sample sizes, and this was especially true for the MCP method.

\section{Estimating Abundance and Density of Species Populations}

Class II research and modeling II attempts to understand the differences in species abundance and/or density among different habitats. For example, it is often desirable to know whether species at risk, such as migratory songbirds, experience lower breeding populations in areas managed for timber harvest compared to areas managed for natural values. When addressing such questions, a great deal of caution 
must be exercised in interpretation and application of results. Although it seems to be simple at first glance, understanding quality of habitat based on numbers of individuals is problematic. Studies at Class II should be grounded in knowledge of species natural history, intraspecific social behavior and, in particular, territorial habits, when applicable. Van Horne (1983) insisted that multi-year intensive demographic studies (Class III) are truly needed to differentiate between source and sink habitat areas for management purposes.

Today, it is recognized that estimates of animal density are not good indicators of habitat quality. Van Horne (1983) alerted researchers to the following concerns:

1. In temperate zones, winter habitat may dictate the carrying capacity of the land, so observations in summertime may not have significant ecological meaning. Site fidelity could result in patterns reflecting past habitat conditions.

2. If dominant individuals secure territories in high quality habitats, subdominants and juveniles may be forced to concentrate in low quality habitat.

3. At least one theoretical model of behavior implies that new immigrants would settle into lower quality habitats to avoid interactions with established individuals.

4. Patchy habitat that allows for movement of individuals as conditions change, habitat generalist species with high reproductive capacity, and habitat that is unpredictable through time all exacerbate potential problems with using simple density estimates for assessing habitat quality (van Horne 1983).

Density may still be a good indication of habitat quality for rare species, especially if seasonal issues are accounted for, and habitat is not patchy (which would increase the likelihood of demographic-based localized extinction, unrelated to habitat quality).

Vickery et al. (1992) tested the hypothesis that population density indicates habitat quality by also measuring reproductive success across habitats of varying densities for three grassland sparrows. At the scale examined, the relationship between density and reproductive success differed among all three species. For the Grasshopper Sparrow (Ammodramus savannarum), reproductive success was lowest in habitats associated with lowest density, and was highest in medium-density habitats. For Savannah Sparrows (Passerculus sandwichensis), as density of territories increased, reproductive success declined significantly. For Vesper Sparrows (Pooecetes gramineus), there was no significant relationship between density and reproductive success, although the pattern was such that density could have been used as an index of habitat quality (Vickery et al. 1992). 
Based on such empirical data, as well as numerous theoretical reasons, managers should not place high value on simple estimates of density when evaluating habitat quality for conservation and management purposes.

\section{Demographic Response}

Detailed demographic data are needed for many Class III questions and analyses, whether correlative models or population viability analysis (PVA; see Population Viability Analysis, page 30). An example of demographic modeling is the Fort Hood Avian Simulation Model (FHASM) developed to aid in habitat management of the golden-cheeked warbler and the black-capped vireo on Fort Hood, Texas. In this complex model, different habitat types were associated with different probabilities of avian presence, reproductive success, and survival, based on a combination of expert knowledge and correlative data from field studies (Trame et al. 1997).

In most cases, demographic models are based upon multi-year studies of marked individuals, in which certain vital rates are measured. The age or size (some measure of "state") of each individual must be measured, along with survival data, and rate of reproduction, over a period of many years. It is important that the method of marking individual animals does not alter their rate of survival or reproduction. The marked individuals should be representative of the population as a whole, so it may be necessary to use a stratified sampling scheme to capture potentially important, but rare, individuals, such as large, old individuals. Each year, the youngest cohort of individuals must be marked and added to the study.

All marked individuals should then be repeatedly located and measured at a regular interval, usually once a year, (unless management questions lead to censuses at multiple seasons). Special procedures may be needed to capture information about certain aspects of species' life histories, for example, data about seed banks and juvenile dispersal and survival require experimental manipulation or special census efforts. Data collection should be repeated as many times as possible. With adequate sampling, the variation in vital rates can be estimated, providing more realistic results to support management decisions.

When sample sizes are small, estimates of survival are likely to be in error. Morris and Doak (2002) advocate a two-step procedure for calculating survival rates for classes of structured populations, as would be needed in a structured population viability analysis (in which more than one demographic state is recognized). First, perform a logistic regression of survival vs. age (or stage or size) with all or most of the data. Then use the regression equation to calculate survival for each class separately. In many cases, the smallest or youngest class(es) should be withheld from 
this procedure. The youngest individuals are likely to experience significantly higher mortality rates during weaning and/or dispersal, and that information should be maintained separately with an independent calculation of survival for the class or classes for which that is pertinent. Scatter plots can reveal sharp discontinuities in vital rates and guide classification decisions when population structure is considered explicitly in a model.

The fertility rate is equal to the average number of offspring produced by individuals (in each class, if population structure is considered) during the interval between census visits. The number must reflect the number of offspring born, regardless of how many survive until the next census following their birth. This normally requires extra visits between census intervals. Some organisms use more than one method of reproduction. Many plants have both sexual and vegetative reproduction, and this may be best handled with separate classes that reflect meaningful differences in survival and growth rates (Morris and Doak 2002).

\section{Population Viability Analysis}

Population viability analysis can be used to predict population responses to habitat, environment, and other factors, such as management, for research in Class II and Class III. Discussion of PVA is included in this section of the document because the output of PVA is focused on population size and viability over time. For extensive, useful instruction on conducting PVA, see Morris and Doak (2002).

PVA should not be conducted with sparse data. It is advisable to have at least 10 years of data before conducting a PVA if the results will be used for important decisions such as legal commitments (Morris and Doak 2002). If a species has a good possibility of becoming a significant management issue in the future (e.g., a species of concern), it is wise to start collecting viability-oriented data as soon as possible so informed scientific decisions can be made later. PVA is appropriate when significant conflicts between conservation and land use exist, when regulatory requirements demand simulation results as a basis for decision-making, and when adequate data has been gathered over a period of time to support such simulation. As discussed later, a PVA with extremely wide confidence intervals may be useful, because it can demonstrate just how little confidence exists in any decision related to species management, and can demonstrate priorities for additional data collection. It is helpful and realistic to adopt the attitude that PVA is never finished and that there is no final word. 


\section{Count-based PVA}

The term "count-based PVA" is used for an analysis of Class II research. The model requires counts of a population over time, but not necessarily in consecutive years. A subset of the population can be used, such as breeding females, but an assumption is made that the proportion of breeding females remains relatively stable through time. Ten census efforts are considered the minimum needed, even for this relatively simple PVA procedure. If census counts were made at regular intervals, an arithmetic mean and sample variance can be calculated on the change in count numbers (Morris and Doak 2002). This will yield metrics associated with population viability and variance in population count changes over time.

If censuses do not occur at regular intervals, linear regression can be used to estimate viability, quantify variance, construct confidence intervals around viability metrics, and assess temporal autocorrelation and outliers in the count data. It offers more information than the arithmetic mean method, and thus, is recommended over the arithmetic mean method even for annual census data.

Count-based PVA methods contain six important assumptions:

1. Negligible density-dependent effects over the predicted timeframe.

2. An absence of demographic stochasticity.

3. An absence of temporal trends in environmental conditions.

4. Environmental conditions are uncorrelated from one year to the next.

5. Environmental variation is small to moderate (no catastrophes, no bonanzas).

6. Error in observation during census counts is negligible (Morris and Doak 2002).

Assumptions 1, 3, and 4 above can be tested through methods that are described in Morris and Doak (2002). When users understand violations of assumptions, the interpretation of results can be modified accordingly. For example, results can be thought of as "optimistic" or "pessimistic," based on any violations of assumptions that are found. Demographic stochasticity can be managed by setting an appropriately high quasi-extinction threshold.

Count-based PVA offers an initial assessment of long-term population viability with low data requirements and simple calculations. It is recommended for Class II management questions when repeated census data are reliable and an initial sense of viability is desired. It is not a procedure for making conservation decisions. However, careful assessment of assumptions allows some insight into the risks posed to populations of conservation interest, especially when used to make comparisons between different populations (Morris and Doak 2002). More sophisticated count- 
based PVAs can be executed as well, which are more robust with respect to the assumptions listed above, and are covered in detail by Morris and Doak (2002).

\section{Demographic PVA}

Demographic (Class III) PVA includes a range of analyses. The following sections discuss single population PVA, multi-site PVA, and spatially explicit, individualbased PVAs. Each type of PVA uses demographic response data of different groups within populations (such as male/female or age-based groups) to predict viability of populations through time. Models in Class III can provide detailed managementoriented results, such as: determining that increasing survival of young is more important for long-term population viability than increasing reproduction of adults.

\section{Single Population PVA}

Working with the structure of populations (i.e., different subsets within populations) requires choosing a basis for classifying individuals into categories. The choice most often is between size, stage, or age. Usually, practical life-history considerations lead to a choice that reflects meaningful differences between classes. For example, species that are indeterminate in growth (e.g., gopher tortoise) are often classified based on size. Species displaying obvious morphological differences during different life history stages, such as larval or juvenile stages, are categorized by stage. A combination of approaches can be used, such as age or stage classes that end with a large class of all individuals above a certain age. An ideal classification choice would be representative of the age/stage structure in nature, be highly correlated with vital rates for the population, and be easy to measure with accuracy and repeatability (Morris and Doak 2002). If a classification metric and discrete classes are difficult to identify, statistical analyses can be used to assist in the process, as well as provide the estimates of vital rates that are needed for the PVA itself. Details about these statistical tests are found in Morris and Doak (2002).

Typical output from PVA includes the population growth rate, or the proportion by which the population will change in size from year to year, and the extinction risk, or "the probability of a population hitting a quasi-extinction threshold by a given time "t"'(White 2000). Another measure, estimating the amount of time before quasi-extinction is reached, can be misleading (Ludwig 1996). Single population PVA can identify important life stages that are critical for population stability or growth. For example, a size-structured demographic model for the desert tortoise (Gopherus agassizii) revealed that survival of large adult females was critical to population stability or growth. In contrast, large improvements in other vital rates would not be nearly as effective (Doak et al. 1994). 
When random processes affecting survival and fertility rates are included in a PVA, random numbers must be generated from a distribution of values in order to produce specific representative vital rates from each step in the simulation. The underlying distribution of values must be chosen. Morris and Doak (2002) discuss three: the beta distribution, the lognormal distribution, and the stretched beta. The beta distribution is correct when vital rates represent binary events, such as survival and even growth rates. Melton et al. (2001) used beta distributions to generate values for adult Red-cockaded Woodpecker (Picoides borealis) survival, juvenile survival, and probability of nesting success. The lognormal distribution, which is bounded by zero and positive infinity, is often used to simulate fertility rates. But, Morris and Doak (2002) recommend use of the stretched beta distribution for this parameter. The stretched beta distribution is a rescaled beta function, having an upper and lower limit defined by the modeler. It provides more realistic values for fertility rates than the lognormal distribution.

Random variable generators can be used to produce vital rate values for individual organisms at each time step. In a Monte Carlo simulation, selection of survival, growth, and fertility replicates is decided by a set of independent random choices, based on the mean vital rates for the appropriate subpopulation class. Often, Monte Carlo simulations are performed when the population or class size is below a certain level, due to calculation constraints. Modelers commonly choose to perform Monte Carlo simulations when numbers of individuals drops to 20 to 100. Morris and Doak (2002) recommend using 50 individuals as a reasonable cutoff value.

\section{Multi-site PVA}

Multi-site PVAs are required when TES management questions concern differences among sites or when tradeoffs between sites are contemplated and managers need to know the importance of protecting different sites. When more than one population (or metapopulation) is included in a model, simulations get very complex. Often, the proper data is not available to support the complexity included in such models. It is essential to work within the context of realistic data limitations as modeling becomes more complicated and detailed. Stith et al. (1996) describe an exercise in multi-site PVA for the Florida Scrub-Jay (Aphelocoma coerulescens). Their book chapter summarizes a state-wide survey to document the distribution of the species, extensive field efforts to quantify dispersal behavior, difficulties in classifying and organizing metapopulation patterns across large distances, the incorporation of field data into a complex multi-site PVA, and specific conservation results (Stith et al. 1996). A relatively simple application of a multi-site model was developed by Doak (1995) to examine the movement between source and sink habitat for the Yellowstone population of grizzly bears (Ursus arctos). This is not a spatially explicit model, but rather incorporates different vital rates for source habitat vs. 
sink habitat and considers movement of bears between the two habitat types and the conversion of source habitat into sink habitat through time. This model revealed that ongoing, slow habitat degradation can result in long lag periods between critical levels of habitat deterioration and detectable change in population sizes, even in the presence of excellent monitoring data (Doak 1995).

Ideally, all of the data needed for a single-site PVA is available for each site, plus movement rates between sites, plus estimates on how fluctuations through time in all vital rates and movement rates are correlated among sites. Since ideal data is rarely if ever available, the practical aspects of data availability in the context of multi-site PVA efforts are discussed below.

Since separate data on survival, growth, and fertility rates are usually not available for multiple sites, modelers often assume that vital rates are the same at all sites, but that carrying capacities differ among sites. In this case, carrying capacity would be estimated for each site through some sort of correlative or expert opinion model, as discussed previously. The simplifying assumption about vital rates underestimates the value of any site contributing significantly more towards species fitness than the site(s) used for vital rate data collection. Another simplifying tactic is to allow many vital rates to be equal across sites, but to gather new data on a subset of vital rates and model those differences explicitly. For example, reproduction may be closely linked to site size and location in passerine birds, and multi-site data could be incorporated for this important factor. With certain well-studied processes, such as reproductive success in passerines, a generally documented relationship could be used in the model in place of gathering new data from the sites of interest. However, this assumption reduces accuracy in the model, since reproductive rates would be based on data from different locations and possibly from different species.

Modelers rarely have sufficient data from multiple sites over sufficient time periods to calculate correlations in vital rates among sites. However, surrogate variables, such as weather data, are often substituted. For example, Lahaye et al. (1994) looked at the correlation between rainfall measured at different weather stations, and then assumed that the strongest possible correlation in growth rates between populations of California Spotted Owl (Strix occidentalis occidetnalis)would be equivalent to the correlation in rainfall patterns. However, the modelers also ran simulations with lesser degrees of correlation and simulations without any correlation in growth rates. Considering all such possibilities can provide a "rough guess as to which populations are most correlated and which are less so" (Morris and Doak 2002). An alternative method is to use data on catastrophic events or bonanzas (very rare events with disproportionate impacts on demographic rates, negative or positive, respectively). Finally, it is reasonable to assume that populations in 
closer proximity will have more correlated vital rates compared to populations across longer distances. Akcakaya and Atwood (1997) used a multi-site model for the California Gnatcatcher (Polioptila californica). They assumed that correlations in vital rates would decline exponentially with distance. They ran several different versions of the model using alternative guesses for the rate of decline. The most conservative overall strategy when guessing about spatial or environmental relationships in vital rates is to assume no negative correlations, and then vary the magnitude of positive correlation rates over a reasonably large range of values.

Multi-site PVAs require data on the rate of movement of individuals between sites. Movement data can be derived from mark-recapture studies that document rates of individual movement between sites. Complications such as different movement rates for males, females, different age classes, or size classes of individuals, and the effects of intervening habitat types are all important. These can be analyzed and incorporated if sufficient sampling effort has occurred. Unfortunately, dispersal rates are often so low that even an aggressive effort will document only a few instances of between-site movement. Individual movement behavior can be used to estimate movement behavior between subpopulations. The calculations are very technical. Turchin (1998) contains details on various methods that can be used to estimate animal movement. In all cases, the very aspect of movement needed for the PVA process, movement across the longest possible distances, is problematic. First of all, the farther an individual moves, the higher the probability of mortality. Difficulty in monitoring movement increases roughly proportionate to the square of the distance (Robert Melton, Ecologist, U.S. Army Engineer Research and Development Center/Construction Engineering Research Laboratory, professional communication, August 2004). Dispersal mortality often must be estimated and included. Secondly, movement behavior across different habitat types, and at the ecotones between them, may be needed for some methods (Morris and Doak 2002).

\section{Spatially Explicit PVA}

Spatially explicit PVAs can be based on population counts or on demographic data. This section describes PVA procedures for models in which the spatial relationships between sites are explicitly defined, usually in a GIS. The count-based, multi-site PVA is based on a transition matrix that includes numbers of individuals at different sites. It is comparable to a demographic transition matrix that would be based on numbers of individuals in different subsets of the population, such as different age classes. Dispersal between sites would be included as well. The results of spatially explicit PVA include output such as the quasi-extinction risk of the population at each site over a specified period of time, making it possible to compare the risks posed at individual sites. Managers can examine the relative effectiveness of conserving different combinations of sites. TES managers can also see how the risk of 
comprehensive extinction declines with the addition of subsequent sites to an overall conservation strategy.

Demographic, spatially explicit PVAs simply include location data for multiple subpopulations to the type of PVA discussed as a single population PVA, above. However, all other parameters may differ among subpopulations. This variability creates considerably more complex models. It is very important to understand the possible correlations in demographic rates among different sites. The model exists as a large transition matrix, including both class- and site-specific demographic rates, and movement probabilities, that also can be class- and site-specific. Analysis is by simulation. Details on spatially explicit demographic PVA are found in Morris and Doak (2002).

The most complex PVA discussed here is the individual-based model. In such a model, the movements and demographic fates of individual organisms are modeled explicitly by computer simulation, usually across a detailed GIS-based habitat map. In this way, the complexity of habitat interrelationships, realistic movement paths, barriers, and responses to habitat can be explicitly considered in the simulation. There is the potential to include more ecological and biological realism. The drawbacks are related to data limitations. This issue is especially critical with the highly complex nature of individual-based models. It is always more important to create an accurate model than it is to include many realistic elements based on guesswork.

An individual-based, grid-based population viability model was created to evaluate the population response of Bachman's Sparrow (Aimophila aestivalis) to various habitat management plans. This model was used to evaluate the effects of a habitat management plan for the conservation of Red-cockaded Woodpeckers, since the two species exist in the same habitat type (Liu et al. 1995). The model included sparrow population dynamics, spatial distributions, dispersal behavior, response to habitat types, and forest growth. Each (simulated) individual sparrow was followed from birth, through dispersal, reproduction, and death. Three alternative forest harvest plans were simulated: random harvest pattern, harvesting oldest stands first, and harvesting clumps of adjacent stands. Important differences were seen in the response of sparrow population dynamics to the three different harvest plans. Simulation results led to specific recommendations for making modifications in habitat management planning to support both Bachman's Sparrow and the Red-cockaded Woodpecker (Liu et al. 1995). Another individual-based population viability model for the Red-cockaded Woodpecker was developed by Walters et al. (2002). 


\section{Modeling the Relationship Between Habitat and Species}

\section{Correlative Approaches}

James (1971) introduced the idea of the niche-gestalt as a way to think about species habitat, and she used multivariate analysis to operationalize Hutchinson's (1957) multi-dimensional niche theory in evaluating habitat. This conceptual link underlies the application of multivariate correlative statistical procedures in evaluating species habitat relationships. The following paragraphs briefly discuss a number of linear multivariate approaches: cluster analysis, discriminant function analysis, principle components analysis, and multiple regression.

Cluster analysis, which encompasses a number of different algorithms, can be used to classify different samples in terms of shared characteristics. For example, 100 habitat locations could be measured for 15 characteristics. Cluster analysis would reveal the degree of similarity among those characteristics and aggregate locations together such that within-group similarity is maximized and between-group similarities are minimized. This type of analysis can determine if a given group can be divided into subgroups based on statistical differences. Cluster analysis is most appropriate for categorical (descriptive) rather than continuous data (James and McCullough 1990). Conservation biologists most frequently use cluster analysis to identify combinations of species with similar habitat requirements. Often, cluster analysis will be imbedded in a larger statistical effort, when grouping is desired. Cluster analysis will create clusters whether or not natural groupings exist, and can be over-interpreted as a result (James and McCullough 1990). Variables all should be of a similar data type (e.g., continuous interval, categorical, etc.), since mixing data types is problematic in cluster analysis. Missing data points are also problematic, so every location must be characterized with the same set of variables. Cluster analysis is also sensitive to outliers. Therefore, exploratory data analysis to locate and remove outliers is highly recommended. Most clustering procedures are biased towards finding hyperspherical or hyperovoid clusters, and are not good at detecting U-shaped or other odd-shaped clusters, even though there is no reason to assume that any data will cluster in a particular shape. In addition, the many different choices among clustering procedures make it difficult to identify the most powerful test for any given application. Performing several different clustering techniques 
and comparing the results is worthwhile. For more details on choice and application of cluster analysis, see McGarigal et al. (2000).

Discriminant function analysis (DFA) tests for multivariate differences among groups determines which variables are most useful for discriminating among groups, determines whether one subset of variables performs equally well as another, and identifies which groups are most alike and most different. As an example, DFA was used to identify characteristics of preferred roost habitats for northern long-eared bats (Myotis septentrionalis) by Menzel et al. (2002). The researchers located 12 roost trees by following 7 radio-tagged lactating bats. They measured 24 variables at the 12 roost locations and at random sites. Stepwise DFA was used to determine which of the 24 variables discriminated among roost and random sites. They identified three variables (i.e., roost height, roost diameter and basal area of nearby snags) that differed among roost and random sites and could be used in future predictive models (Menzel et al. 2002).

Discriminant function analysis requires one or more categorical grouping variables (random vs. roost site in the above example), and two or more continuous discriminating variables (the 24 variables measured). Discriminating variables should be continuous for the technique to work efficiently. The discriminating variables can be dependent or independent. The sampling groups must be mutually exclusive and every sampling location, regardless of group membership, must be measured on the same set of variables. It is not required that the number of sampling entities in each group be the same, but, generally, the greater the disparity in group sample sizes, the lower the effectiveness of the DFA in distinguishing among groups. Each data set needs to have at least two sampling locations per group and at least two more sampling locations than the number of discriminating variables (note that this last requirement was violated by Menzel et al. 2002). For more details on choice and application of discriminant analysis, see McGarigal et al (2000).

Principal components analysis (PCA) is used to condense information from a large number of (potentially) explanatory variables into a smaller set called principal components that are defined as linear combinations of the original variables describing maximum variation among individual sampling locations. In PCA, the discriminating factors are calculated to capture variation within the data set as a whole, rather than being calculated to maximize discrimination among pre-defined groups. For example, 23 potential explanatory variables were assembled from vegetation structure and composition data to support a management goal of identifying thresholds in forest bird response to habitat alteration. After screening via PCA and Pearson's correlation analysis, the number of relevant variables was reduced to 16 (Guénette and Villard 2005). In this example, the data were assumed to be multivariate normal, with independent samples, careful elimination of true outliers, 
and linearity among variables. Since PCA is used as an exploratory data reduction method, violation of these assumptions may be tolerated. PCA is most appropriate when applied to data describing narrow, linear environmental gradients. If more complex patterns in environmental gradation are suspected, alternative ordination procedures such as detrended correspondence analysis or canonical correspondence analysis are more appropriate. Two specific sample size requirements have been suggested for PCA: $\mathrm{N}=4 \mathrm{P}$ (Hair et al. 1987) and $\mathrm{N}=20+3 \mathrm{P}$ (Johnson 1980), where $\mathrm{P}$ is the number of variables and $\mathrm{N}$ is the number of samples. For more details on choice and application of PCA, see McGarigal et al (2000).

Multiple regression examines the strength of relationship between one dependent variable and multiple potential explanatory (independent) variables. Saveraid and others used multiple regression to elucidate the relationship between bird occurrences and abundances and independent variables from remotely sensed landscape, or habitat-level data (Saveraid et al. 2001). They concluded that satellite data is appropriate for determining broad areas where species are likely located. However, multiple regression established that both landscape metrics and habitat-level data are needed to predict species presence or absence.

When using multiple regression, it is necessary to implement a procedure to select the best single model out of all possibilities. Currently, use of information-theoretic criteria procedures (e.g., Akaike Information Criterion or Bayesian Information Criterion) are recommended over the alternatives because they control for violations of assumptions better than other procedures (MacNally 2000). See Burnham and Anderson (2002) for more details.

Several design requirements are important when using multiple regression. Sample sizes must be at least five times the number of independent variables. True outliers in the data must be removed. The independent variables cannot be highly correlated (i.e., multicollinear). Multicollinearity can seriously limit the ability of the model to make accurate predictions. When independent variables are highly correlated, final models retain variables that do not actually have any ecological meaning, which increases Type I error rates. For more details on choice and application of multiple regression, see McGarigal et al (2000).

Autologistic regression can model spatial autocorrelation explicitly by including an extra covariate that is derived from data in neighboring areas (grid cells), and thus offers a significant improvement over other correlation techniques. Augustin et al. (1996) introduced this procedure in a grid-based model to predict deer distribution. Since autologistic methods require data in every grid cell, Augustin et al (1996) also reported on use of the Gibbs sampler and a modified version of the Gibbs sampler, to populate unsurveyed grid cells. Their assessment (comparison of random 20 per- 
cent census data with full census data) showed that the autologistic model, paired with the modified Gibb's sampler, was superior to the ordinary logistic model for estimating the spatial distribution of deer. The ordinary logistic model performed better at predicting the overall number of squares occupied by deer. The use of autologistic regression models is recommended for predicting species distributions following grid-based census efforts. The procedure reported by Augustin et al. (1996) is appropriate when resources are limited, such as survey and mapping studies at Class I.

General linear models (GLMs) extend classical linear regressions by offering a greater variety of relationships between explanatory and response variables, and without assuming a normal distribution. The important advantage is that relationships can be described that are potentially much more consistent with ecological theory (Austin 2002). For example, class variables (such as 0,1 categorical classes) can be used as independent variables. However, a functional form must be declared before the analysis is run. In some other techniques, this is not necessary and the form of the relationship can be derived from the data itself (Elith and Burgman 2002). GLMs are used to model resource selection patterns (see Resource Selection Studies, page 42) as well as correlations between environmental data and species occurrence. The common structure of GLM relates the probability of a particular resource (habitat) being used to multiple quantifiable conditions.

Data with error distributions that depart from normality may be analyzed with general additive models (GAMs). GAMs express the relationship between explanatory and response variables in nonparametric, smooth functions that are fitted to the data. Thus, GAMs can be useful when the relationship is not easily defined in parametric form and the form need not be specified (Elith and Burgman 2002). Austin and Meyers (1996) found that GAM was preferable to GLM for modeling tree occurrences, due to its flexible nature and smoothing function. An example of GAM application is found in Leathwick (1998), in which 12 tree species presence/absence data is analyzed against many different environmental and spatial variables. The presence/absence data was assumed to display a binomial error distribution. The results were interpreted to indicate that four focal species could potentially occur over much larger areas than they currently occupy. These species also displayed weak spatial patterns in their relationship to the environment, leading to the hypothesis that the species are not at equilibrium with their environment. The species are most likely existing in locations where they have been able to persist over time, rather than exploiting new locations.

Neural networks (using a back-propagation algorithm) can be used to develop nonlinear relationships between multiple variables, and do not require prior knowledge about the nature of the relationship between variables (Lusk et al. 2002). 
Through "brute-force" computing power, random attempts eventually fit the data to the best function, always a very complex, nonlinear, and non-intuitive equation. Functions are not constrained to simple curve form, and the process is nonparametric. Thus, neural networks provide a satisfactory option for analysis in the natural sciences. A reasonable introduction to neural network processes can be found in Lusk et al. (2002). Lek et al. (1996) provides an example paper on the use of neural networks and compares their output to that of linear multiple regression. Eleven independent variables were measured in 205 different study units of a river system. In this example, neural network analysis outperformed the multiple regression, even with transformed variables, when the $R$-squared values are compared ( $R$ squared $=0.96 \mathrm{vs}$. $R$-squared $=0.72$; comparisons of the neural net were made using a subset of the training data). Lusk et al. (2002) report a similar comparison between multiple regression and neural network simulation for data relating Northern Bobwhite counts to weather data. Although their criteria for comparison indicated that the multivariate regression model explained more variation in observed patterns, the neural network provided valuable insight into the importance of all utilized variables. For example, the multivariate regression model heavily weighted winter precipitation (more than 54 percent of the total $R$-squared value came from this one variable). Only two other variables contributed more than 10 percent of the total R-squared. The neural network worked with 5 different variables rather evenly, each contributing between 10 and 20 percent of the total $R$-squared value. This provided valuable insight into the responses of Northern Bobwhite (Colinus virginianus) to many different weather variables. Austin (2002) reminds us that comparisons of statistical modeling procedures are only possible when the actual "truth" is known. For greater insight into the dangers of comparing statistical techniques, see Austin (2002). There exists an important risk of over-fitting a neural network to data points, decreasing accuracy in any application.

Heglund (2002) cautioned that advances in analytical, correlative techniques are of questionable use if the true underlying relationship between habitat and response is non-linear. Several authors have recommended non-linear means of modeling organism response (Austin 1976, Gauch and Chase 1974, Heglund et al. 1994, Whittaker 1975). In addition, if modeling is based only on correlation, it offers no insight into the underlying mechanisms for species response, and thus cannot provide trustworthy input into management plans. Improved understanding of causative mechanisms will modify the choice of variables to be examined and most likely will lead to improved correlative models as well (Heglund 2002). In 1980, Karr (1980) warned that biologically important relationships are the important goal we seek in our data, not just statistical relationships. 
For more information on predictive habitat modeling techniques, see Guisan et al. (2002), Guisan and Zimmermann (2000), Morrison et al. 1998, and Munoz and Felicisimo (2004).

\section{Resource Selection Studies}

Resource selection studies attempt to compare the availability of habitat to the selection and use of habitat, thus providing an indication of habitat requirements for the organism of interest. Results of resource selection studies can be used to map probabilities of species occurrences, predict abundance in different habitats, estimate local population size, or project demographic responses in different habitats. However, in all cases, the main objective is to measure the degree of use of habitat and to compare it to "available" habitat. The following discussion distinguishes among three types of resource selection studies based on important differences in study design. First, habitat selection can be evaluated for the entire population, without knowledge of individual animal choice. Haney and Solow (1992) used this design type when they compared the relative amount of sampling effort in each of four habitat types with the proportion of marine bird numbers in each of the four habitats. Second, individual animals are monitored for habitat choice, but the availability of habitat is measured at an aggregate, population level. Roy and Dorrance (1985) compared the availability of various habitat types within individual coyote home ranges with overall habitat availability across the entire extent of the study. Third, individual choices of habitat type are measured and compared to the habitat available at an individual level (for example, that found within each individual home range). Rolley and Warde (1985) used this method when they monitored the home range habitat use of individual bobcats (Lynx rufus) and compared those choices with the proportions of available habitat within each of those same home range areas. Thomas and Taylor (1990) and Alldredge et al. (1998) review a variety of design approaches and statistical procedures used in resource selection studies. One good source of information is Manly et al. (2002).

Manly et al. (2002) provide a comprehensive list of hypothesis tests used to evaluate whether or not resources have been selected preferentially, along with important references for each test. Several hypothesis tests are discussed later in this section. Alternatively, data from resource selection studies can be used to develop mathematical resource selection functions (RSFs; Boyce and McDonald 1999). RSFs are mathematical equations that are proportional to the probability of use of a habitat type (or any resource unit).

Resource selection studies may sample habitat through random plots or points, or may use maps to delineate and measure the area of various habitat types. Measur- 
ing habitat availability can be more problematic than measuring animal use. Resource selection studies assume that all individuals have free and equal access to resources. If habitat availability and use are measured separately for each individual animal, this assumption causes no concern. However, when studies are attempting to measure choices over areas larger than home ranges, such as choices related to placement of home ranges in a larger landscape, this assumption becomes problematic (Garshelis 2000). This latter objective is likely to be fairly common in the context of Army TES management studies. In these cases, all habitat types in the area chosen for study will be considered available to the individual organisms. In these studies, several ecological processes can invalidate the assumption of uniform habitat availability. For example, home ranges may become established near natal areas based on familiarity with the resources and nearby individuals. Thus, only a small portion of "potential" habitat may be searched when choices are made (Garshelis 2000).

More significantly, each individual may not have all habitat types in their home ranges. The only choices available to individual animals are the particular combinations of habitat types currently existing on the landscape. Individuals cannot create an ideal home range by combining types and amounts of habitat to suit their needs (Garshelis 2000).

A random sample of animals is assumed, which usually means that animals captured or surveyed are assumed to be representative of the entire population. Availability of habitat is assumed to be known (when habitat types are mapped) and to be constant through time. It is important to evaluate this assumption if data are gathered over long timeframes compared to the biology of the habitat or species of interest. It is important that resightings are accurate, so observed habitat use is correct. For example, if habitat patches are very small, the triangulation error in relocating radio-collared animals may cover more than one habitat type (Alldredge et al. 1998).

When individual animals are not marked, it is problematic to assume that evidence of greater density correlates with higher true densities of animals. Just as with point count surveys, differences in detectability among habitat types can affect apparent densities and create misleading results. Therefore, it is prudent to first assess detectability in different habitats and then adjust results so a corrected estimate of density is considered (Thomas and Taylor 1990).

If animals are gregarious (attracted to habitats because they are attracted to each other), related (and affected by common learning experiences), or from the same social group (in which a dominant animal determines the habitat use for all members), the assumption of individuals reflecting independent habitat choices is vio- 
lated. In this case, groups such as herds can be used as the sampling unit. Likewise, locations of pack animals that are dependent upon each other for hunting should not be considered as independent sampling of the environment (Garshelis 2000). In contrast, Millspaugh et al. (1998) state that when individual animals are located together due to the presence of a resource (rather than simply the presence of other animals), the sightings should be considered independent. This could occur, for example, in winter, when food, water, or shelter resources become scarce. Millspaugh et al. (1998) recommend tests to evaluate the independence of habitat choices of associated individuals.

It is best if the ecological and behavioral factors affecting habitat selection are identified before resource studies are designed. Demographic survival and/or reproductive data can be collected and compared among habitat types (Alldredge et al. 1998, Garshelis 2000) to better estimate the ecological significance of habitat choices. However, relationships between habitat factors and fitness are likely complex, characterized by thresholds, asymptotes, and inflection points. Studies often are complicated by unexpected variation and confounding factors (Garshelis 2000). Based on these requirements, resource selection studies are inherently Class II or Class III efforts.

Pooling individual selection (response) data for analysis is not recommended. When pooling individual data is avoided, variation in selection rates can be identified, and differences among different ages or sexes may be revealed, both of which greatly facilitate Class III modeling efforts (see Thomas and Taylor 1990 for discussion). When individual choices are examined for variation, it becomes possible to posit whether the population as a whole is making similar resource selection decisions (Alldredge et al. 1998). Estimates of variation within individuals and among individuals are also possible (R.Melton, professional communication, August 2004).

In resource selection studies, like all other studies, it is important to match the scale of the study to the management goal, so that relevant results can be generated. For the purposes of learning habitat associations, studies that track individual animals will be most useful if they avoid focusing on detailed choices within TES home ranges or territories. The more common goal for TES management on military installations is to predict relative abundances among different habitats. This reflects decisions that individual animals make in defining territories and home ranges within the larger landscape. The best way to ensure a relevant scale is to compare resource choices against habitat options at an extent larger than home range size, rather than comparing resource choices against the available habitat within home ranges. 
If a resource selection study is going to be used to estimate population size, it is assumed that the limiting factors that influence the distribution and abundance of the organism are known; the relevant data on key habitat variables is needed (Manly et al. 2002). Additionally, the study requires the significant assumption that the extent of habitat use is positively associated with fitness of the organism in that habitat. It is recommended that managers confirm habitat value with fitness data to support any decision process using habitat selection patterns to predict abundance or population estimates.

Alldredge and Ratti (1986) compared four statistical tests for resource selection studies. They found that regardless of test, a sample size of 20 individual animals was needed to reduce Type II errors to an acceptable level. They also recommended that limiting the number of habitats types to less than 10 would reduce error rates.

Several statistical tests can be used to evaluate resource selection (see Table 1). If individual animals are not marked and relocated, then one of the Chi-squared tests is required. If habitat availability is known and completely mapped, then it is appropriate to use the Chi-square goodness-of-fit test and related multiple comparisons (Byers et al. 1984, Cherry 1996, Neu et al. 1974). The Chi-squared goodnessof-fit test, log-linear model test (Heisey 1985), and the large sample normal test (Iverson et al. 1985) should not be used if the habitat is sampled with points or plots. In this case, the Chi-square test of homogeneity is always appropriate (with or without tracking of individual animals). The Johnson (1980), Friedman (1937; see Conover 1980), Quade (1979), or compositional analysis procedures (Aebischer et al. 1993) are possible when individual animals are marked and re-surveyed (Thomas and Taylor 1990, Alldredge et al. 1998).

The Chi-squared goodness-of-fit test requires independence of observations, when relocating the same animal. The Johnson procedure, the Friedman test, and compositional analysis do not require independence in relocation data (Alldredge et al. 1998).

Dasgupta and Alldredge (1998) review the misuses of the Chi-square goodness-of-fit test, including situations in which it should not be used at all. They introduce a "dependency" parameter for use when multiple animal sightings can occur, and discuss its use in a Columbian Sharp-tailed Grouse (Tympanuchus phasianellus columbianus) study. Friedman's, compositional analysis and Johnson's tests assume that individual animals make habitat choices independently. However, the Johnson procedure and compositional analysis have extensions that can be used to consider social organisms. 
Table 1. Statistical methods for testing resource selection by animals.

\begin{tabular}{|l|l|l|l|l|l|}
\hline Consideration & Neu et al. & Johnson & Friedman's & Quade & Compositional \\
\hline $\begin{array}{l}\text { Habitat } \\
\text { availability }\end{array}$ & $\begin{array}{l}\text { Must be known } \\
\text { (mapped } \\
\text { completely) }\end{array}$ & $\begin{array}{l}\text { Can be } \\
\text { estimated }\end{array}$ & $\begin{array}{l}\text { Can be } \\
\text { estimated }\end{array}$ & $\begin{array}{l}\text { Can be } \\
\text { estimated }\end{array}$ & $\begin{array}{l}\text { Can be } \\
\text { estimated }\end{array}$ \\
\hline $\begin{array}{l}\text { Independence } \\
\text { of relocations }\end{array}$ & Required & Not required & Not required & & Not required \\
\hline $\begin{array}{l}\text { Individual } \\
\text { animals must } \\
\text { be relocated? }\end{array}$ & no & yes & yes & yes & yes \\
\hline $\begin{array}{l}\text { Questionable } \\
\text { habitat types }\end{array}$ & $\begin{array}{l}\text { Poses a } \\
\text { problem }\end{array}$ & $\begin{array}{l}\text { Do not pose } \\
\text { a problem }\end{array}$ & $\begin{array}{l}\text { Do not pose } \\
\text { a problem }\end{array}$ & $\begin{array}{l}\text { Do not pose } \\
\text { a problem }\end{array}$ & $\begin{array}{l}\text { Do not pose } \\
\text { a problem }\end{array}$ \\
\hline $\begin{array}{l}\text { Unit sum } \\
\text { limitation }\end{array}$ & $\begin{array}{l}\text { Poses a } \\
\text { problem }\end{array}$ & $\begin{array}{l}\text { Poses a } \\
\text { problem }\end{array}$ & $\begin{array}{l}\text { Poses a } \\
\text { problem }\end{array}$ & $\begin{array}{l}\text { Does not pose } \\
\text { a problem }\end{array}$ \\
\hline Replicate unit & Relocations & Animal & Animal & Animal \\
\hline $\begin{array}{l}\text { Dependencies } \\
\text { in animal } \\
\text { choices }\end{array}$ & & $\begin{array}{l}\text { Assume } \\
\text { independent } \\
\text { choices }\end{array}$ & $\begin{array}{l}\text { Assume } \\
\text { independent } \\
\text { choices }\end{array}$ & $\begin{array}{l}\text { Assume } \\
\text { independent } \\
\text { choices }\end{array}$ \\
\hline
\end{tabular}

The most commonly used test, the Chi-squared goodness-of-fit method, is influenced by the somewhat arbitrary decision to include or exclude habitat types from analysis. If a highly avoided habitat type is included, it can lead to the conclusion that other habitats are preferred. If the avoided type is taken out of the analysis, the results may change dramatically for the remaining habitat types (Thomas and Taylor 1990, Alldredge and Ratti 1986). One technique for handling this situation is to analyze results with and without any questionable habitat types, to understand its impact on results.

In discussing this problem for compositional analysis, Aebischer et al (1993) suggest merging habitat types, eliminating types that are not used by many animals in the study, and/or substitution of a very small value in place of some zero values. See Aebischer et al. (1993) for more details.

Johnson (1980) introduced an alternative, rank-based method to avoid problems with inclusion of habitat types that are common in the environment, but rarely used by animals. Johnson's test requires resource use observations of individual animals, although independence of relocations of an individual animal is not required (Alldredge et al. 1998). A rejection of the null hypothesis using Johnson's method should be followed by the Waller-Duncan simultaneous comparison procedure (Waller and Duncan 1969; Alldredge and Ratti 1986).

Friedman's and Quade's tests also are rank-based methods requiring observations of individual animals, and are resilient to inclusion or exclusion of questionable habitat types in the design. Fisher's least significant difference procedure for pair- 
wise comparisons should follow the rejection of the null hypothesis (Alldredge and Ratti 1986).

The unit-sum constraint refers to the fact that use of all habitat types must sum to 1.0 for each individual animal. Thus, choice of one habitat type automatically affects use of all other habitat types. Aebischer et al. (1993) asserts that the procedures of Friedman, Quade, and Neu et al. are undesirable since they fail to explicitly treat this issue. Compositional analysis utilizes a log-ratio transformation on habitat use ratios to render them independent with regard to the unit-sum for habitat choices (Aebischer et al. 1993). Johnson's test is also capable of dealing with this issue.

When performing compositional analysis, the choice of test depends in part upon the distribution of data. Compositional analysis can test the same range of hypotheses as MANOVA and multiple regression, but when applied to habitat selection data such as those described in Aebischer et al (1993), it closely resembles Johnson's (1980) procedure. Unlike Johnson's method, compositional analysis can be extended to assess differences between blocks of elements such as sex, age, and seasonal timing, or the relationship between habitat use and continuous variables such as food supply (Aebischer et al. 1993).

Compositional analysis assumes that each animal provides an independent sampling of habitat. If the number of radio locations varies among animals, the logratios should be weighted accordingly. Aebischer et al. (1993) recommends weighting the log-ratios by the square root of $n$, when $n$ is the number of locations for that animal.

Alldredge and Ratti (1986) compared the statistical basis and performance of four methods: the Chi-squared goodness-of-fit test, the Friedmans' test, the Johnson test and the Quade test. Details about hypotheses tested, further discussion of assumptions, and sample size requirements can be examined in Alldredge and Ratti (1986). The choice of statistical test should be made based on the hypothesis tested and the necessary assumptions. Among the four compared tests, there was no clear choice of superior method in all simulated cases. All four methods effectively controlled Type I error rates. The occurrence of Type II error rates was dependent upon the number of habitats, number of animals, number of observations per animal, and the magnitude of differences detected. The Chi-squared goodness-of-fit test and the Quade method performed well in simulations with few habitats (less than 10), at least 20 individual animals marked, and 50 locations per animal. When the number of habitat choices was large, Johnson and Friedman's tests performed best. Johnson's method failed to detect differences when the differences between availability and selection were large, but the relative rank orderings were identical. All meth- 
ods led to larger Type II errors as greater numbers of habitats are included in the analysis. All methods suffered from high Type II error rates when few animals were located 15 or fewer times (Alldredge and Ratti 1986).

For compositional analysis, Aebischer et al. (1993) recommend an absolute minimum total sample size of 6 animals. It is preferable to use more than 10 individuals, and, ideally, more than 30 individuals. If subpopulations are to be compared, each category must have more than 10 individuals. All sampling must be done "at the same time," unless time of year is modeled explicitly (or can be ignored). Optimal allocation of sampling effort between numbers of animals tagged and number of relocations is based upon between-animal variation in habitat use, and subsampling efficiency (i.e., how well habitat use is estimated). If animal choices are highly variable, it is best to tag more animals and use fewer relocations in order to adequately capture between-animal variation. If home ranges are to be calculated, it is useful to know how many radio points are needed to achieve stability in home range estimates. A pilot study is helpful on both of these accounts (Aebischer et al. 1993).

\section{Knowledge-based Models}

Knowledge-based modeling relies on partial data (usually gathered together from published literature and local data sources) and the experienced opinions of species and/or habitat experts. Such information is captured through interviews and workshops, and implemented via a wide variety of simulation environments and commercial or custom-developed software. There is no inherent limit to how species response is modeled using knowledge-based methods. Any shape to the relationship can be used. Modeling can be based upon environmental constraints rather than correlations or ideal conditions. The following discussion is limited to knowledgebased models that are spatially explicit in some form.

Two examples of knowledge-based models are provided for illustration purposes: (1) a model at Class I to predict likely occurrence of the Yellow-billed Cuckoo (Coccyzus americanus occidentalis; Greco et al. 2002), and (2) a model at Class II of Louisiana Waterthrush (Seirius motacilla) habitat (Brooks 1997).

Greco et al. (2002) utilized the following (spatially-explicit) variables to develop a knowledge-based model of Yellow-billed Cuckoo habitat: species of vegetation, patch area, patch width, patch distance-to-water, the ratio of high vegetation to medium/low vegetation within patch, and the ratio of young floodplain to old floodplain within patch. Variables were quantified and the model was implemented within a GIS. In this instance, species of vegetation was taken from a 1997 land cover survey. If the land cover category was called "riparian" and was known to be a certain 
successional age, it was assumed to be the vegetation type of interest, willowcottonwood floodplain forest (Greco et al. 2002). The variable related to forest structure (high vegetation vs. medium and low vegetation) was based on two separate research studies. The two studies found that Yellow-billed Cuckoo nesting was most frequent in vegetation below $20 \mathrm{~m}$ high. Therefore, the model specifies that each patch must possess some amount of vegetation in the category of "medium" or "low" height in order to support breeding Yellow-billed Cuckoos. Yet another independent study of the breeding territories of four pairs of Yellow-billed Cuckoos was used to calibrate the forest structure variable. After all variables were assessed, the geometric mean was calculated with equal weighting to determine a habitat quality score, which was then visualized on a grid-based overlay for comparison with the original land-cover map.

The knowledge-based model of Louisiana Waterthrush habitat developed by Brooks (1997) was initially based on a literature review and consisted of nine variables. Fifty-three sites were surveyed for vegetation type and presence-absence of Waterthrush. Results led to modifications of the model. An entirely new set of 26 sites was surveyed the same year to validate the revised model. Additional projects were planned to compare model output with breeding activity and nesting success of the species, to provide further refinement (Brooks 1997). As this example demonstrates, knowledge-based models have raised awareness of the importance of validation, calibration, and issues of uncertainty in application of models for conservation decisionmaking. Even models that are based on some statistical analysis usually include expert opinion and judgment as well, leading to the need for validation.

The most important risk in using knowledge-based models is the potential for each model to become large, complicated, and impossible to truly test for accuracy. Since many different variables and equations can be easily included, it is difficult to keep track of uncertainty in the various components of the model. Once output is generated, it is difficult to decide what it means or how much it should be trusted. When using knowledge-based models, it is best to develop small, tightly focused models on an ad hoc basis. These models would be developed in-house or with a closely affiliated organization, and should be relatively inexpensive due to their limited scope. This approach will help maintain installation familiarity with the model's components, assist in validation and error assessment, and ensure that models are applied to questions the underlying data and model structure were designed to address. 


\section{An Alternative Paradigm - Modeling Constraints with CART}

O'Connor (2002) advocates using classification and regression tree (CART) analysis for modeling species distributions because it supports a paradigm of modeling constraints rather than a paradigm of modeling ideal conditions for predicting species response to the environment. CART recursively divides the data set into subsets, based on constraints, not correlation. He gives a typical example whereby species occurrence may be based upon July temperatures exceeding 25 degrees C, elevation below $500 \mathrm{~m}$, croplands forming no more than 15 percent of local land cover, and/or average forest patches greater than 2500 ha (O'Connor 2002).

\section{Mapping Spatial Data and Understanding Spatial Structure in Data}

It is possible to follow point sampling with various techniques to interpolate point data over a continuous surface (map). Legendre and Fortin (1989) provide a more complete discussion than can be included in this report. Geostatistical and other spatial interpolation procedures consider the data collected at all random or systematic points in a region, and generate estimates for points not sampled. Many programs use a smoothing procedure that produces results for a uniform grid over the region of interest. The use of two such procedures, inverse distance weighting and kriging, is discussed by Sauer et al. (1995) specifically for use with bird abundance mapping following point count surveys. For developing distribution maps of TES from a point count data, systematic sampling may produce better results than random sampling. Greater sampling effort through replications and more sampling points will reduce sampling bias during point surveys. If an area is known to support higher densities of organisms, then sampling effort should be higher in the vicinity of that area (Sauer et al. 1995). The following details about spatial interpolation of ecological data are important:

1. Extrapolation between known points must be viewed with caution since detection problems can distort results significantly (see Sauer et al. 1995 for examples).

2. Phenomena that occur at higher resolution than the survey will not be accurately modeled. For example, rare species or species sampled at the edge of their range will be poorly mapped.

3. Trend surface analysis can be structured to accommodate spatial variation in sampling intensity and different observers and the existence of missing data. Many ecologists use trend surface analysis to remove large spatial trends, and follow with additional spatial analysis, such as kriging, on the residual (unexplained) variation through space (Legendre and Fortin 1989). Many other interpolation methods cannot adjust for these common biases (Sauer et al. 1995). 
4. Kriging utilizes local data to estimate the value of unsampled locations, by considering data autocorrelation. It is a more refined method than trend surface analysis (see examples in Legendre and Fortin 1989). Kriging results include a map of estimated values and a map of standard deviation, which can be used to optimize additional field sampling for areas with higher uncertainty.

It is important to consider the spatial structure (lack of independence in point data through space) in ecological data. Many statistical procedures (e.g., all parametric statistical tests) assume a lack of spatial structure, while other procedures (such as interpolation procedures) make use of the information. Understanding the spatial structure of data is important if data is collected for a specific reason (i.e., mapping) and then later extended for additional purposes (i.e., characterizing habitat).

Two forms of spatial independence exist among sample points: conditional independence and unconditional independence. Conditional independence is related to the presence (or absence) of individuals at one point affecting the probability of presence (or absence) of individuals at nearby points. For example, if vocalizations of male birds at one point affect the probability of vocalizations of male birds at the next nearest sample point (in this case, negatively), there is a lack of conditional independence. Adequate spacing of points is required to prevent this problem. Unfortunately, determining adequate distances requires pilot empirical studies. Unconditional independence, or autocorrelation, is caused when pairs of nearby points exhibit more similar responses compared to pairs of more distant points (Pendleton 1995). Semivariograms can be used to determine optimum spacing distances to reduce this dependence.

Spatial analysis should always be included as an integral part of Class II and III research projects. All sampled data should be tested for autocorrelation, and spatial structure should be described and considered in further analysis. In some cases, spatial structure should be removed (i.e., detrending) and statistics should be completed on residuals. However, in any effort to map species distributions, spatial structure should not be removed, it should be explicitly utilized in refining and understanding species response to environmental variation. 


\section{Sources of Error and the Importance of Accuracy Assessment}

Error in models of species habitat relationships can be caused by many factors, including:

1. insufficient sample size,

2. measurement error in species survey data and mapped environmental data (sampling error),

3. incorrect scale of sampling or of spatial data, and

4. failure to incorporate critical ecological variables in the model.

Quantification of model accuracy helps managers to determine the applicability of models for various purposes, especially legal decisionmaking. It also may identify weaknesses that require correction with further effort. Different techniques and/or models can be compared through accuracy assessment, as well.

Sometimes, sensitivity analysis is offered as a substitute for full model validation. However, a model that does not demonstrate sensitivity to changes in parameter values may not be sensitive enough to make accurate predictions (Conroy and Moore 2002). Sensitivity analyses are recommended for the identification of variables requiring further refinement and calibration to fit the model more closely to a specific situation. Validation should be performed to meet a goal of accuracy assessment.

Fielding (2002) reminds us that ecology is a challenging science, contending, as it does, with many stochastic factors and interacting events. Even if accurate and unbiased variables can be identified, they may not be measurable. Thus, one should not be surprised or discouraged by moderate levels of accuracy from modeling efforts. Yet, it is essential to assess and discuss accuracy considerations when management decisions must be made and defended.

The best measure of accuracy assessment is always to apply the model to entirely independent, novel data and assess how well the model functions to predict results. Often, independent data is not available, and the single available data set is divided into uneven parts; the larger portion is used to develop or train the model, while the smaller set is used to test the model. Huberty (1994) offers a formula for determin- 
ing the optimal ratio of training set to testing set. The reduction in training sample size created by this process often reduces the accuracy of the resultant model. Alternatively, resampling procedures such as the jackknife can be used to estimate confidence limits for models (Fielding 2002). Significant references on resampling procedures include Davison and Hinkley (2003) and Efron and Tibshirani (1993). A summary of resampling methods for the purposes of validation can be found in Verbyla and Litvaitis (1989). In important cases with significant ecological, political, or legal risks, it is recommended that installations always develop an independent data set for accuracy assessment.

\section{Accuracy of Results from Class I Studies}

\section{Confusion Matrices and Derived Measures}

Distributional studies incur two types of mistakes: errors of commission and omission. Commission errors occur when the model predicts species presence in a location where the species does not occur. Omission errors occur when the model predicts absence where the species does in fact occur. The occurrence of such errors is evaluated through the use of confusion matrices. Confusion matrices list the proportion of results predicted correctly (both present and absent), and the proportion of results predicted incorrectly (both commission and omission errors; see Table 2; Fielding 2002). Notice that this exercise requires the continuous "probability of occurrence" values output from a model to be divided into a group that predict occurrence and a group that predicts absence. This entails setting an arbitrary threshold value for dividing the range of output. Several derived measures can be used to quantify accuracy from a confusion matrix (Fielding 2002). Although such measures are simple to calculate, they are not necessarily the best method to use. These measures are all dependent upon the threshold value chosen. It is better to choose a means of assessing accuracy that is independent of the threshold for predicting occurrence, (such as the graphical methods below; Fielding 2002).

The correct classification rate (CCR) is very simple, but includes ratios of commission and omission errors to calculate the overall rate of correct classification. The positive predictive power measures the ratio of true positives to the total number of positive predictions (both correct and incorrect). Kappa $(K)$ is the proportion of specific agreement, and is often used to assess whether a model performed better than chance. Landis and Koch (1977) suggested that a value of $K>0.4$ indicated "good agreement". The normalized mutual information (NMI) measure may be preferable over Kappa in cases where one class dominates the sample. Kappa is sensitive to sample size and unreliable if class sizes are very uneven; NMI does not share these limitations (Fielding 2002). 
Modelers can gain insight into commission errors by calculating likelihood-ofoccurrence-ranks (LOOR) before running a validation exercise (Schaefer and Krohn 2002). LOOR values indicate which species are likely to be missed during field validation surveys, based on rarity or a reclusive nature (Boone and Krohn 1999). In some cases, rates of commission errors may appear substantially higher than they truly are, and model accuracy may be doubted in cases when accuracy is much higher, possibly at acceptable levels. Careful examination of such a situation is recommended whenever a model appears to have high commission errors and the focus species is not abundant and easily detected.

Table 2. Example of a confusion matrix and some derived accuracy measures (taken from Fielding 2002).

\begin{tabular}{|l|c|c|}
\hline \multirow{2}{*}{ Actual } & \multicolumn{2}{|c|}{ Predicted } \\
\cline { 2 - 3 } & $\boldsymbol{+}$ & - \\
\hline $\boldsymbol{+}$ & $\mathbf{9 5}$ & $\mathbf{2 0}$ (omission) \\
\hline $\boldsymbol{1}$ & $\mathbf{5}$ (commission) & $\mathbf{8 0}$ \\
\hline CCR & \multicolumn{2}{|c|}{0.875} \\
\hline PPP & \multicolumn{2}{|c|}{0.826} \\
\hline Kappa & \multicolumn{2}{|c|}{0.750} \\
\hline NMI & \multicolumn{2}{|c|}{0.480} \\
\hline
\end{tabular}

\section{Logistic Regression}

Logistic regression can be run, fitting a line to the relationship between probability of occurrence values and the observation of whether the species was present or absent from the corresponding site. This method was used to evaluate a (different) logistic regression model and a Mahalanobis distance model, each predicting avian species presence for multiple species over a large area of the southern United States, as part of a larger study to compare modeling approaches and validation methods (Dettmers et al. 2002). For most species, model accuracy appeared higher when evaluated through logistic regression compared to measures such as CCR (probably due to the problems with threshold values, mentioned above; Dettmers et al. 2002).

\section{Graphical Methods}

Several graphical methods can be used to examine the accuracy of Class I model output; those discussed here are illustrated in Pearce et al. (2002). A graph can be made by plotting predicted probabilities associated with occupied sites against the predicted probabilities associated with unoccupied sites. The probability of occurrence is plotted on the $\mathrm{x}$-axis, while the proportion present (or absent) is plotted on 
the y-axis. Discrimination plots provide two types of information. They reveal the range of predicted values obtained from the validation exercise; a well-refined model will make predictions spanning the entire zero-to-one range of probabilities. A discrimination histogram reveals how well a model discriminates between occupied and unoccupied sites (Pearce et al. 2002). A good model will lead to relatively higher predicted values for occupied sites compared to unoccupied sites.

Receiver operating characteristic (ROC) plots were developed as a signal processing technique. The plot is obtained by plotting all true positive proportions on the yaxis against the values for proportion of commission errors on the x-axis. A curve is generated by running the model repeatedly, using a large number of different threshold values. The area under this curve expresses the model's discrimination ability. An area measure of 0.5 indicates that the model performed the same as a random model. As discrimination ability increases, the area measure will increase up to a maximum of 1.0. Values of 0.7 or 0.75 and above are often associated with acceptable model performance (Pearce et al. 2002, Elith and Burgman 2002). Pearce and Ferrier (2000) provide additional details for interpretation and use of the ROC plot curve.

A calibration plot is created by first dividing the values for predicted probability into equally sized classes, such as 10 equal classes from 0 to 1 . Then, the proportion of occupied sites within each class is plotted (on the y-axis) against the median predicted value for the class (on the x-axis). A well-calibrated model will lead to a plot that closely follows a 45-degree line, where the observed proportion of occupied sites equals the median predicted value for the class. To quantify the degree of calibration, three statistics can be calculated: the Cox statistic, the bias measure, and the spread measure (Pearce et al. 2002).

\section{Accuracy of Class II and III Results}

There are two forms of variability in counting organisms within habitat patches: within-site variability and between-site variability. Between-site variability derives from the differential use of habitat by the organisms themselves. Within-site variability lies in the counting process itself: sampling error, bias, and miscounts. Two counting efforts of the same patch of habitat would not necessarily lead to the same counts, even if the same number of organisms were present each time. This form of variability contributes error in statistical tests and conclusions. Link et al. (1994) estimated that at least 14 out of 98 species of birds displayed greater within-site variability than between-site variability, when estimated by repeated breeding bird survey counting procedures during one season. Species with lower counts tended to have higher proportion of variability coming from within-site variability. 
Habitat suitability, abundance, or density indices can be validated by comparing index values with mark-recapture derived population size estimates. One review of HSI validation efforts found that the most common types of statistical tests for comparing model output (habitat quality values ranging from 0.0 to 1.0) with validation data were correlation and regression analyses (Roloff and Kernohan 1999). It is important that validation take place across the entire range of possible output values from the model. This enables a test of predictive power across different habitat conditions, demonstrating model robustness.

Laymon et al. (1985) presented initial validation results for their spotted owl HSI model. First, the HSI values were compared between 70 sites in which owls were known to occur, and 70 random sites. Sites known to support spotted owls had significantly higher HSI values. Second, a vocal survey imitating spotted owl calls was conducted across sites with a range of HSI values: 14 sites each scoring unsuitable, low, moderate, or high HSI scores. The results showed a significant increasing trend in owl call response with increasing HSI values (Laymon et al. 1985).

Morrison et al. (1987) validated bird abundance models by collecting new data the following 2 years; first on the same plots (not independent data) and second, on different plots within the same forest (independent data). Validation consisted of comparing the percentage of plots for which the original model over-or under-estimated bird abundance. Confidence intervals were calculated on model output and the relationship between field data and output confidence intervals was noted and considered. The authors judged that the model was adequate for predicting the presence/absence of a species, but not abundance. Using the second year's data, the model underestimated abundance in 17 of 21 bird species, although validation data fell within the confidence intervals for every species for which a confidence interval could be calculated. Predictions ranged from 100 percent underestimate to 194 percent overestimates; the three predictions with the most extreme errors were present in very low abundances across all years of the study (Morrison et al. 1987).

Due to the difficulties in interpreting abundance data, studies of research in Class II should be validated with surrogates for estimating fitness, such as reproduction or survival (Roloff and Kernohan 1999). See the Appendix for specific recommendations related to study design and validation considerations.

\section{Reducing Observation Error}

Observation error is variation in census counts caused by researcher inability to count precisely the numbers of individuals within a designated observation area. General guidelines (Morrison and Doak, 2002) for reducing observation error for count-based censuses (and other field studies as well) include: 
1. Use the first year of data collection as a trial run on which to base long-term sampling strategy and allocation of effort. During this first year, repeat sampling through time, and oversample through space to gain insight into the incremental reduction in variation offered by additional efforts. Use several different sampling designs and compare results.

2. Maximize consistency with careful documentation of protocol. The same person should be in charge of training field crews over time for as long as possible. Succeeding leaders also need careful training by the previous leader. It is helpful if specialized skills are not needed by field crews. Also, measure inter-observer variation.

3. A stratified random sample handles spatial variation in density estimates well, whether that variation is due to actual difference in density, or due to habitatspecific differences in detectability.

4. If it is not possible to count all individuals, choose the most visible subset of the population to census.

5. Methods for collecting and recording data should be easy to understand and easy to quantify. (All taken from Morris and Doak 2002).

It is important to quantify errors while the census occurs. Data should be maintained at the finest degree of detail possible (such as replicate transects). Some degree of replication should be included at least in some years. By repeating sampling in the same location at very close intervals of time, variation can be safely assumed to be due largely to observation error (though pseudoreplication must be avoided). Such exercises are needed at periods of high species population density and low species population density, to account for differences in error related to density. Sampling effort, such as number of person-days spent searching, should be recorded. The identity of different observers should always be recorded and maintained as well (Morris and Doak 2002). Morris and Doak (2002) provide some specific formulae and directions to account for observation error in count-based censuses.

\section{Managing Uncertainty}

Morris and Doak (2002) list several recommendations for handling uncertainty in PVA models; the list is helpful for planning any complex Class II or III modeling effort.

1. Avoid building a complex model if available data is sparse. Ten years of census data are recommended for developing a count-based PVA, as "this amount of data stands a reasonable chance of providing at least a qualitative sense of population viability". It has been recommended that 5 to 10 years of demographic data be collected to make predictions regarding extinction for each year into the future that you want to make predictions. Thus, to make predictions for 5 years into the 
future, managers need 25 to 50 years of data (Fieberg and Ellner 2000). Morris and Doak (2002) recommend a minimum of 4 years of data (three annual transitions in vital rates) for a demographic PVA. Multi-species models should be based on at least 2 surveys on at least 20 sites. For stochastic models that include migration between subpopulations, 4 years of data are recommended. For spatially explicit models, "the bar must be set substantially higher than for any other kind of PVA model" (Morris and Doak 2002).

2. Model output should always be presented with confidence intervals. Confidence intervals can be calculated by sampling variable values from the appropriate probability distributions, by using bootstrapping techniques or by using Bayesian techniques. Very broad confidence intervals suggest that adequate data is not available for the development of a formal model.

3. Do not attempt to project population viability far out into the future. The confidence intervals around probability of extinction, for example, expand to encompass all values from 0 to 1 as the timeframe expands into the future. Simple, well-justified models are better when used to make fairly short-term predictions.

4. Always consider how potential factors that have been omitted might cause output to be pessimistic or optimistic. If the model is kept simple, it is particularly important to think about the factors omitted. This helps to ensure proper interpretation and application of results.

5. Whenever possible, consider multiple models to assess uncertainty. It is best to use all well-fitting models to make management decisions. This approach recognizes the fact that we really don't know what model best describes a population.

6. Always consider the modeling process to be a work in process, not the final word. Additional data should always be collected. This allows reconsideration of assumptions, improved estimates of the model variables, and possibly the addition of new factors into the model structure.

\section{Accuracy of Class III Modeling Results}

Validation of Class III models is difficult. Just as with simpler species-habitat relationship models, a subset of the data can be used to develop the model. A second subset of data can then used to validate the accuracy of the model output. However, this method can greatly reduce the ability of the model because data sets are often small, due to the labor-intensive nature of demographic data collection. Alternatively, output from a model can be used to make predictions about a novel population. The fact remains that we don't know what model best describes a population, and when multiple models are fitted with the same data, they often do not produce similar predictions related to population viability or extinction probabilities. The best method for managing this uncertainty is to never consider absolute model results. It is essential to bear in mind that model results are not completely accurate 
and should not be interpreted as absolute measures of TES viability. Results provide a means for comparison, exposing relative degrees of risk and viability for management consideration. 


\section{Literature Cited}

Aebischer, N.J., P.A. Robertson, and R.E. Kenward. 1993. "Compositional analysis of habitat use from animal radio-tracking data.” Ecology 74: 1313-1325.

Akcakaya, H.R. and J.L. Atwood. 1997. "A habitat-based metapopulation model of the California gnatcatcher.” Conservation Biology 11: 422- 434.

Alldredge, J.R. and J.T. Ratti. 1986. "Comparison of some statistical techniques for analysis of resource selection.” Journal of Wildlife Management 50: 157- 165.

Alldredge, J.R., D.L. Thomas, and L.L.McDonald. 1998. "Survey and comparison of methods for study of resource selection.” Journal of Agricultural, Biological and Environmental Statistics 3:237-253.

Andreassen, H.P., R.A. Ims, N.C. Stenseth, and N.G. Yoccoz. 1993. "Investigating space use by means of radiotelemetry and other methods: a methodological guide," pp 589-618 in N.C. Stenseth and R.A. Ims, eds, The Biology of the Lemmings. Academic Press, London.

Augustin, N.H., M.A. Mugglestone and S.T. Buckland. 1996. "An autologistic model for the spatial distribution of wildlife.” Journal of Applied Ecology 33: 339-347.

Austin, M.P. 2002. "Case studies in the use of environmental gradients in vegetation and faunal modeling: theory and practice in Australia and New Zealand,” pp 73-82 in Scott, M.J., P.J. Heglund and M.L. Morrison, eds, Predicting Species Occurrences: Issues of Accuracy and Scale. Island Press, Washington, DC.

Austin, M.P. 1976. “On non-linear species response models in ordination.” Vegetatio 33:33-41.

Austin, M.P. and P.C. Heyligers. 1989. "Vegetation survey design for conservation: gradsect sampling of forests in north-eastern New South Wales.” Biological Conservation 50: 1332.

Austin, M.P. and P.C. Heyligers. 1991. "New approach to vegetation survey design: gradsect sampling," pp 31-36 in C.R. Margules and M.P. Austin, eds, Nature conservation: cost effective biological surveys and data analysis. CSIRO Australia, Melbourne, Australia.

Austin, M.P. and J.A. Meyers. 1996. "Current approaches to modeling the environmental niche of eucalypts: implication for management of forest biodiversity." Forest Ecology and Management 85: 95-106.

Baja, S., D.M. Chapman, and D. Dragovich. 2002. "A conceptual model for defining and assessing land management units using a fuzzy modeling approach in GIS environment."

Environmental Management 29: 647-661. 
Bender, L.C., G.J. Roloff and J.B. Haufler. 1996. "Evaluating confidence intervals for habitat suitability models." Wildlife Society Bulletin 24: 347-352.

Berry, J.K. 1991. "You can't see the forest for the trees...but on the other hand, you can't see the trees for the forest.” GIS World Magazine, GIS World, Inc., Fort Collins, Colorado October, 1991

Boone, R.B and W.B. Krohn. 1999. "Modeling the occurrence of bird species: are the errors predictable?" Ecological Applications 9: 835-848.

Boyce, M.S. and L.L. McDonald. 1999. "Relating populations to habitats using resource selection functions." Trends in Ecology and Evolution 14: 268-272.

Brooks, R.P. 1997. "Improving habitat suitability index models." Wildlife Society Bulletin 25: 163167.

Burnham, K. P. 1981. "Summarizing remarks: Environmental influences.” pp 324-325 in C. J. Ralph and J. M. Scott, eds. Estimating numbers of terrestrial birds. Studies in Avian Biology No. 6.

Burnham, K. P., and D. R. Anderson. 2002. Model Selection and Multimodel Inference: a Practical Information-theoretic Approach. 2nd ed. Springer, New York.

Burnham, K.P., D.R. Anderson, G.C. White, C. Brownie, and K.H. Pollock. 1987. "Design and analysis experiments for fish survival experiments based on capture-recapture." American Fisheries Society Monograph 5: 260-278.

Burt, W.H. 1943. "Territoriality and home range concepts as applied to mammals." Journal of Mammology 24: 346-352.

Byers, C.R., R.K. Steinhorst, and P.R. Krausman. 1984. "Clarification of a technique for the analysis of utilization-availability data.” Journal of Wildlife Management 48: 1050-1053.

Carter. S.L., C.A Haas, and J.C. Mitchell. 1999. "Home range and habitat selection of bog turtles in southwestern Virginia.” Journal of Wildlife Management 63:853-860.

Cherry, S. 1996. "A comparison of confidence interval methods for habitat use-availability studies.” Journal of Wildlife Management 60: 653-658.

Clark, J.D., J.E. Dunn, and K.G. Smith. 1993. "A multivariate model of female black bear habitat use for geographic information systems.” Journal of Wildlife Management 57(3): 519-526.

Cochran, W.G. 1977. SamplingTechniques. Wiley Press, New York, NY.

Colwell, R.N. 1983. Manual of Remote Sensing. Falls Church, VA.

Congalton, R.G. 1988. "A comparison of sampling schemes used in generating error matrices using remote sensing and geographic information systems." Geocarto International 3: 2333. 
Conover, W.J. 1980. Practical Nonparametric Statistics. John Wiley and Sons, New York, NY.

Conroy, M.J. and C.T Moore. 2002. "Wildlife habitat modeling in an adaptive framework: the role of alternative models," pp 197-204 in Scott, M.J., P.J. Heglund and M.L. Morrison, eds, Predicting Species Occurrences: Issues of Accuracy and Scale. Island Press, Washington, DC.

Corsi F., I. De Leeuw, A. Skidmore, 2000. “Species distribution modelling with GIS” pp. 389-434 in Boitani L. and T.K. Fuller eds. Research Techniques in Animal Ecology. Columbia University Press, New York.

Curran, P.J. and H.D. Williamson. 1986. "Sample size for ground and remotely sensed date." Remote Sensing of the Environment 20: 31-41.

Cyr, A., D. Lepage, and K. Freemark. 1995. "Evaluating point count efficiency relative to territory mapping in cropland birds," pp 69-74 in C.J. Ralph, J.R. Sauer, and S. Droege, eds, Monitoring bird populations by point counts. U.S. Department of Agriculture, Forest Service General Technical Report, PSW-149. USDA Pacific Southwest Research Station, Albany, CA.

Dalke, P.D. and P.R. Sime. 1938. "Home and seasonal ranges of the eastern cottontail in Connecticut." Transactions of the North American Wildlife Conference 3: 659-669.

Dasgupta, N. and J.R. Alldredge. 1998. "A multivariate X2 analysis of resource selection data." Journal of Agricultural, Biological, and Environmental Statistics 3: 323-334.

Davison, A. C., and D. V. Hinkley. 2003. Bootstrap methods and their application. Reprinted with corrections. ed. Cambridge University Press, Cambridge, UK ; New York, NY, USA.

Dettmers, R., D.A. Buehler, and J.B. Bartlett. 2002. "A test and comparison of wildlife-habitat modeling techniques for predicting bird occurrence at a regional scale," pp 607-616 in Scott, M.J., P.J. Heglund and M.L. Morrison, eds, Predicting Species Occurrences: Issues of Accuracy and Scale. Island Press, Washington, DC.

Dixon, K.R. and J.A. Chapman. 1980. "Harmonic mean measure of animal activity areas." Ecology 61: 1040-1044.

Doak, D.F. 1995. "Source-sink models and the problem of habitat degradation: general models and applications to the Yellowstone grizzly.” Conservation Biology 9: 1370-1379.

Doak, D., P. Kareiva and B. Klepetka. 1994. "Modeling population viability for the desert tortoise in the western Mojave desert.” Ecological Applications 4: 446-460.

Dooley, J.L., Jr. and M.A. Bowers. 1998. "Demographic responses to habitat fragmentation: experimental tests at the landscape and patch scale.” Ecology 79: 969-980.

Dreisbach, T.A., J.E. Smith, and R. Molina. 2002. "Challenges of modeling fungal habitat: when and where do you find chanterelles?” pp 475-482 in Scott, M.J., P.J. Heglund and M.L. Morrison, eds, Predicting Species Occurrences: Issues of Accuracy and Scale. Island Press, Washington, DC. 
Dunn, C.P., D.M. Sharpe, G.R. Guntenspergen, F. Stearns, and Z. Yang. 1991. "Methods for analyzing temporal changes in landscape pattern,” pp 173-198 in M.G. Turner and R.H. Gardner, eds, Quantitative Methods in Landscape Ecology. Springer-Verlag, New York, NY.

Dunning, J.B.Jr., D.J. Stewart, B.J. Danielson, B.R. Noon, T.L. Root R.H. Lamberson, and E.E. Stevens. 1995. "Spatially explicit population models: current forms and future uses." Ecological Applications 5:3-11.

Eastman, J.R. 1997. Idrisi. Clark Labs for Cartographic Technology and Geographic Analysis, Worcester, England.

Efron, B., and R. Tibshirani. 1993. An introduction to the bootstrap. Chapman \& Hall, New York.

Elith, J. and M. Burgman. 2002. "Predictions and their validation: rare plants on the central highlands, Victoria, Australia,” pp 303-314 in Scott, M.J., P.J. Heglund and M.L. Morrison, eds, Predicting Species Occurrences: Issues of Accuracy and Scale. Island Press, Washington, DC.

Fieberg, J. and S.P. Ellner. 2000. "When is it meaningful to estimate an extinction probability?" Ecology 81: 2040-2047.

Fielding, A.H. 2002. "What are the appropriate characteristics of an accuracy measure?" pp 271280 in Scott, M.J., P.J. Heglund and M.L. Morrison, eds., Predicting Species Occurrences: Issues of Accuracy and Scale. Island Press, Washington, DC.

Friedman, M. 1937. "The use of ranks to avoid the assumption of normality implicit in the analysis of variance." Journal of the American Statistical Association 32: 675-701.

Garshelis, D.L. 2000. "Delusions in habitat evaluation: measuring use, selection and importance," pp 111-164 in Boitani, L. and T.K. Fuller, eds, Research Techniques in Animal Ecology: Controversies and Consequences. Columbia University Press, New York, NY.

Gauch, H.G., Jr. and G.B. Chase. 1974. "Fitting the Gaussian curve to ecological data." Ecology 53: 446-451.

Gillison, A.N. and K.R.W. Brewer. 1985. "The use of gradient directed transects or gradsects in natural resource surveys.” Journal of Environmental Management 20: 103-127.

Greco, S.E., R.E. Plant, and R.H. Barrett. 2002. "Geographic modeling of temporal variability in habitat quality of the yellow-billed cuckoo on the Sacramento River, miles 196-219, California,” pp 183-196 in Scott, M.J., P.J. Heglund and M.L. Morrison, eds, Predicting Species Occurrences: Issues of Accuracy and Scale. Island Press, Washington, DC.

Guénette, J.S. and M.A. Villard. 2005. "Thresholds in forest bird resonse to habitat alteration as quantitative targes for conservation.” Conservation Biology 19: 1168-1180.

Guisan, A., T. C. Edwards, and T. Hastie. 2002. "Generalized linear and generalized additive models in studies of species distributions: setting the scene.” Ecological Modelling, 157:89-100. 
Guisan, A., and N. E. Zimmermann. 2000. "Predictive habitat distribution models in ecology." Ecological Modelling, 135:147-186.

Hair, J. F., R. E. Anderson, and R. L. Tatham. 1987. Multivariate data analysis. Second edition. Macmillan, New York, New York, USA.

Haney, J. and A. Solow. 1992. "Testing for resource use and selection by marine birds." Journal of Field Ornithology 63: 43-52.

Hansteen, T.L., H.P. Andreassen, and R.A. Ims. 1997. "Effects of spatiotemporal scale on autocorrelation and home range estimators." Journal of Wildlife Management 61: 280290.

Heglund, P.J. 2002. "Foundations of species-environment relations," pp 35-42 in Scott, M.J., P.J. Heglund and M.L. Morrison, eds, Predicting Species Occurrences: Issues of Accuracy and Scale. Island Press, Washington, DC.

Heglund, P.J., J.R. Jones, L.H. Fredrickson, and M.S. Kaiser. 1994. "Use of boreal forested wetlands by Pacific loons (Gavia pacifica Lawrence) and horned grebes (Podiceps auritus L.): relations with limnological characteristics." Hydrobiologia 279/280: 171-183.

Heisey, D.M. 1985. “Analyzing selection experiments with log-linear models.” Ecology 66: 17441748.

Henebry, G.M. and J.W. Merchant. 2002. "Geospatial data in time: limits and prospects for predicting species occurrences,” pp 291- 302 in Scott, M.J., P.J. Heglund and M.L. Morrison, eds, Predicting Species Occurrences: Issues of Accuracy and Scale. Island Press, Washington, DC.

Hill, K.E. and M.W. Binford. 2002. "The role of category definition in habitat models: practical and logical limitations of using Boolean, indexed, probabilistic, and fuzzy categories,” pp 97-106 in Scott, M.J., P.J. Heglund and M.L. Morrison, eds, Predicting Species Occurrences: Issues of Accuracy and Scale. Island Press, Washington, DC.

Hokit, D.G., B.M. Stitch and L.C. Branch. 1999. "Effects of landscape structure in Florida scrub: a population perspective." Ecological Applications 9(1): 124-135.

Huberty, C.J. 1994. Applied Discriminant Analysis. John Wiley and Sons, New York, NY.

Hurlbert, S.H. 1984. "Pseudoreplication and the design of ecological field experiments." Ecological Monographs 54: 187-211.

Hutchinson, G.E. 1957. “Concluding remarks.” Cold Harbor Symposium on Quantitative Biology 22: $415-427$.

Iverson, G.C., P.A. Vohs, and T.C. Tacha. 1985. "Habitat use by sandhill cranes wintering in western Texas.” Journal of Wildlife Management 49: 1074-1083.

James, F.C. 1971. "Ordinations of habitat relationships among breeding birds." Wilson Bulletin 83: $215-236$. 
James, F.C. and C.E. McCullough. 1990. "Multi-variate analysis in ecology and systematics: panacea or Pandora's box?” Annual Review of Ecology and Systematics 21: 129-166.

Johnson, D.H. 1980. "The comparison of usage and availability measurements for evaluating resource preference." Ecology 61:65-71.

Jones, K.B. 1986. "Data types," pp 11-28 in A.Y. Cooperrider, J.B. Raymond and H.R. Stuart, eds, Inventory and Monitoring of Wildlife Habitat. U.S. Department of the Interior, Bureau of Lands, Denver, CO.

Karr, J.R. 1980. "History of the habitat concept in birds and the measurement of avian habitats," pp 991-997 in R. Nohring, ed, Acta Internationalis Congressus Ornithologici, Verlag der Deutschen Ornithologen-Gesellschaft, Berlin, Germany.

Kelly, J. F., and B. Van Horne. 1997. "Effects of food supplementation on the timing of nest initiation in Belted Kingfishers.” Ecology 78: 2504-2511.

Kenward, R. 1987. Wildlife Radio-tagging: Equipment, Field Techniques and Data Analysis. Academic Press, London.

King, A.W. 1991. "Translating models across scales in the landscape," pp 479-517 in M.G. Turner and R.H. Gardner, eds, Quantitative methods in landscape ecology. Springer-Verlag, New York, New York.

King, A.W., A.R. Johnson and R.V. O'Neill. 1991. "Transmutation and functional representation of heterogeneous landscapes." Landscape Ecology 5: 239-253.

LaGro, J.Jr. 1991. "Assessing patch shape in landscape mosaics." Photogrammetric Engineering and Remote Sensing 57: 285-293.

Lahaye, W.S., R.J. Gutierrez and H.R. Akcakaya. 1994. "Spotted owl metapopulation dynamics in Southern California.” Journal of Animal Ecology 63: 775-785.

Landis, J.R. and G.C. Koch. 1977. "The measurement of observer agreement for categorical data." Biometrics 33: 159-174.

Lauga, J. and J. Joachim. 1992. "Modelling the effects of forest fragmentation on certain species of forest-breeding birds." Landscape Ecology 6: 183-193.

Laymon, S.A., H. Salwasser, and R.H. Barrett. 1985. Habitat Suitability Index Models: Spotted Owl. United States Fish and Wildlife Service, Biological Resources Program, Biological Report 82(10.113), Washington, DC.

Laymon, S.A. and J.A. Reid. 1986. "Effects of grid-cell size on tests of a spotted owl HSI model," pp 93-96 in J. Verner, M.L. Morrison, and C.J. Ralph, eds, Wildlife 2000: Modeling Habitat Relationships of Terrestrial Vertebrates. University of Wisconsin Press, Madison, WI.

Leathwick, J.R. 1998. “Are New Zealand's Nothofagus species in equilibrium with their environment?" Journal of Vegetation Science 9: 719-732. 
Legendre, P. and M-J. Fortin. 1989. "Spatial pattern and ecological analysis.” Vegetatio 80: 107138.

Lek, S., M. Delacoste, P. Baran, I. Dimopoulos, J. Lauga and S. Aulagnier. 1996. “Application of neural networks to modeling nonlinear relationships in ecology." Ecological Modelling 90: 39-52.

Leopold, A. 1937. “A conservationist in Mexico.” American Forests 43: 118-120.

Link, W.A., R.J. Barker, J.R. Sauer, and S. Droege. 1994. "Within-site variability in surveys of wildlife populations." Ecology 75: 1097-1108.

Liu, J., J.B. Dunning, Jr., and H.R. Pulliam. 1995. Potential effects of a forest management plan on Bachman's Sparrows (Aimophila aestivalis): linking a spatially explicit model with GIS.” Conservation Biology 9: 62-75.

Ludwig, D. 1996. "Uncertainty and the assessment of extinction probabilities." Ecological Applications 6: 1067-1076.

Lusk, J.J., F.S. Guthery, and S.J. DeMaso. 2002. "A neural network model for predicting northern bobwhite abundance in the rolling red plains of Oklahoma,” pp 345-356 in Scott, M.J., P.J. Heglund and M.L. Morrison, eds, Predicting Species Occurrences: Issues of Accuracy and Scale. Island Press, Washington, DC.

MacKenzie, D.I. and W.L. Kendall. 2002. "How should detection probability be incorporated into estimates of relative abundance?" Ecology 83: 2387-2393.

MacNally, R. 2000. "Regression and model-building in conservation biology, biogeography, and ecology: the distinction between - and reconciliation of — "predictive" and "explanatory" models." Biodiversity and Conservation 9: 655-671.

Manly, B.F.J., L.L. McDonald, D.L. Thomas, T.L. McDonald, and W.P. Erickson. 2002. Resource Selection by Animals: Statistical Design and Analysis for Field Studies. Kluwer Academic Publishers, Boston, MA.

McGarigal, K., S. Cushman and S. Stafford. 2000. Multivariate Statistics for Wildlife and Ecology Research. Springer-Verlag, New York, NY.

Meesters, E.H., R.P.M. Bak, S. Westmacott, M.Ridgley and S. Dollar. 1998. "A fuzzy logic model to predict coral reed development under nutrient and sediment stress." Conservation Biology 12: 957-965.

Melton, R. H., L.A. Jette, T.J. Hayden, and T. A. Beatty. 2001. Population Viability of Avian Endangered Species: the PVAvES Program. U.S. Army Corps of Engineers Engineer Research and Development Center Technical Report ERDC/CERL TR-01-7, ADA388185 ERDC/CERL, Champaign, IL.

Menzel, M.A., S.F. Owen, W.M. Ford, J.W. Edwards, P.B. Wood, B.R. Chapman, and K.V. Miller. 2002. "Roost tree selection by northern long-eared bat (Myotis septentrionalis) maternity colonies in an industrial forest of the central Appalachian mountains." Forest Ecology and Management 155: 107-114. 
Millspaugh, J.J., J.R. Skalski, B.J. Kernohan, K.J. Raedeke, G.C. Brundige, and A.B. Cooper. 1998. "Some comments on spatial independence in studies of resource selection." Wildlife Society Bulletin 26: 232-236.

Mohr, C.O. 1947. "Table of equivalent populations of North American small mammals." American Midland Naturalist 37: 223-249.

Moilanen, A. and I. Hanski. 1998. "Metapopulation dynamics: effects of habitat quality and landscape structure.” Ecology 79: 2503-2515.

Monmonier, M.S. 1982. Computer-assisted Cartography: Principles and Prospects. Prentice Hall, Englewood Cliffs, NJ.

Morris, W.F. and D.F. Doak. 2002. Quantitative Conservation Biology: Theory and Practice of Population Viability Analysis, Sinauer Associates, Inc., Sunderland, MA.

Morrison, M.L., I.C. Timossi, and K.A. With. 1987. "Development and testing of linear regression models predicting bird-habitat relationships." Journal of Wildlife Management 51: 247253.

Morrison, M. L., B. G. Marcot, and R. W. Mannan. 1998. Wildlife-habitat relationships: concepts \& applications. 2nd ed. University of Wisconsin Press, Madison, WI.

Munoz, J., and A. M. Felicisimo. 2004. "Comparison of statistical methods commonly used in predictive modelling.” Journal of Vegetation Science, 15:285-292.

Murphy, D.L. 1985. "Estimating neighborhood variability with a binary comparison matrix." Photogrammetric Engineering and Remote Sensing 51: 667-674.

Neu, C.W., C.R. Byers, and J.M. Peek. 1974. "A technique for analysis of utilization-availability data." Journal of Wildlife Management 38: 541-545.

O’Connor, R.J. 2000. "Expert Systems, Fuzzy Logic, and Coral Reef Development under Environmental Stress.” Conservation Biology 14: 904-906.

O’Connor, R.J. 2002. "The conceptual basis of species distribution modeling: time for a paradigm shift?” pp 25-34 in Scott, M.J., P.J. Heglund and M.L. Morrison, eds., Predicting Species Occurrences: Issues of Accuracy and Scale. Island Press, Washington, DC.

Pearce, J.L. and S. Ferrier. 2000. "Evaluating the predictive performance of habitat models developed using logistic regression.” Ecological Modelling 133: 225-245.

Pearce, J.L., L.A. Venier, S. Ferrier and D.W. McKenney. 2002. "Measuring prediction uncertainty in models of species distribution,” pp 383- 390 in Scott, M.J., P.J. Heglund and M.L. Morrison, eds., Predicting Species Occurrences: Issues of Accuracy and Scale. Island Press, Washington, DC.

Pearl, J. 2000. Causality: models, reasoning, and inference. Cambridge University Press, Cambridge, U.K. and New York. 
Pedlar, J.H., L. Fahrig, and H.G. Merriam. 1997. "Raccoon habitat use at two spatial scales." Journal of Wildlife Management 61: 102-112.

Pendleton, G.W. 1995. "Effects of sampling strategy, detection probability, and independence of counts on the use of point counts," pp 131-133 in C.J. Ralph, J.R. Sauer, and S. Droege, eds., Monitoring bird populations by point counts. USDA Forest Service General Technical Report, PSW-149. USDA Pacific Southwest Research Station, Albany, CA.

Pielou, E.C. 1977. Mathematical Ecology. John Wiley and Sons, New York, NY.

Quade, D. 1979. "Using weighted rankings in the analysis of complete blocks with additive block effects." Journal of the American Statistical Association 74: 680-683.

Ralph, C.J., J.R. Sauer, and S. Droege. 1995. Monitoring Bird Populations by Point Counts USDA Forest Service General Technical Report, PSW-149. USDA Pacific Southwest Research Station, Albany, CA.

Ranney J.W., M.C. Bruner, and J.B. Levenson. 1981. "The importance of edge in the structure and dynamics of forest islands,” pp 67-96 in R.L. Burgess and D.M. Sharpe, Forest island dynamics in man-dominated landscapes, Springer-Verlag, New York, NY.

Rastetter, E.B., A.W. King, B.J. Cosby, G.M. Hornberger, R.V. O’Neill, and J.E. Hobbie. 1992. "Aggregating fine-scale ecological knowledge to model coarser-scale attributes of ecosystems." Ecological Applications 2:55-70.

Richards, J.A. 1986. Remote Sensing: Digital Analysis. Springer-Verlag, Berlin.

Ricketts, T.H. 2001. "The matrix matters: effective isolation in fragmented landscapes." The American Naturalist 158: 87-99.

Ripple, W.J., G.A. Bradshaw, and T.A. Spies. 1991. "Measuring landscape pattern in the Cascades Range of Oregon, USA.” Biological Conservation 57: 73-88.

Riitters, K.H., R.V. Oneill, C.T. Hunsaker, J.D. Wickham, D.H. Yankee, S.P. Timmins, K.B. Jones, and B.L. Jackson. 1995. "A factor analysis of landscape pattern and structure metrics." Landscape Ecology, 10:23-39.

Roberts P.R., and H.J. Oosting. 1958. "Responses of venus fly trap (Dionaea muscipula) to factors involved in its endemism.” Ecological Monographs 28: 193-218.

Rolley, R.E. and W.D. Warde. 1985. "Bobcat habitat use in southeastern Oklahoma." Journal of Wildlife Management 49: 913-920.

Roloff, G.J. and B.J. Kernohan. 1999. "Evaluating reliability of habitat suitability index models." Wildlife Society Bulletin 27: 973- 985.

Romme, W.H. 1982. "Fire and landscape diversity in subalpine forests of Yellowstone National Park.” Ecological Monographs 52: 199-221. 
Roy, L.D. and M.J. Dorrance. 1985. "Coyote movements, habitat use, and vulnerability in central Alberta.” Journal of Wildlife Management 49: 307-313.

Rubinoff, J., Sescienski, S. and W. Woodson. 2004. Installation Summaries from the FY 2003 Survey of Threatened and Endangered Species on Army Lands. SFIM-AEC-TS-TR 2004005, Army Environmental Center, Aberdeen Proving Ground, MD.

Saab, V. 1999. "Importance of spatial scale to habitat use by breeding birds in riparian forests: a hierarchical analysis." Ecological Applications 9(1): 135-151.

Samuel, M.D., D.J. Pierce, and E.O. Garton. 1985. "Identifying areas of concentrated use within the home range." Journal of Animal Ecology 54: 711-719.

Sauer. J.R., B.G. Peterjohn, and W.A. Link. 1994. "Observer differences in the North American Breeding Bird Survey.” Auk 111: 50-62.

Sauer, J. R., G. W. Pendleton, and S. Orsillo. 1995. "Mapping of bird distributions from point count surveys.” pp 151-160 in C. J. Ralph, J. R. Sauer, and S. Droege, eds., Monitoring Bird Populations by Point Counts, USDA Forest Service, Pacific Southwest Research Station, General Technical Report PSW-GTR-149.

Saveraid, E.H., D.M. Debinski, K.Kindscher and M.K. Jakubauskas. 2001. "A comparison of satellite data and landscape variables in predicting bird species occurrences in the Greater Yellowstone Ecosystem, USA.” Landscape Ecology 16: 71-83.

Schaefer, S.M. and W.B. Krohn. 2002. "Predicting vertebrate occurrences from species habitat associations: improving the interpretation of commission error rates," pp 419-428 in Scott, M.J., P.J. Heglund and M.L. Morrison, eds., Predicting Species Occurrences: Issues of Accuracy and Scale. Island Press, Washington, DC.

Schoener, T.W. 1981. "An empirically based estimate of home range." Theoretical Population Biology 20: 281-325.

Schulz, T.T. and L.A. Joyce. 1992. “A spatial application of a marten habitat model.” Wildlife Society Bulletin 20: 74-83.

Shaw, Denice M., and Samuel F. Atkinson. 1990. "An Introduction to the Use of Geographic Information Systems for Ornithological Research.” The Condor 92: 564-570.

Shipley, B. 2000. Cause and Correlation in Biology : a User's Guide to Path Analysis, Structural Equations and Causal Inference. Cambridge University Press, Cambridge, U.K. and New York.

Skidmore, A. 2002. Environmental Modelling with GIS and Remote Sensing. Taylor \& Francis, New York.

Smallwood, K.S. 2002. "Habitat models based on numerical comparisons," pp 83-96 in Scott, M.J., P.J. Heglund and M.L. Morrison, eds., Predicting Species Occurrences: Issues of Accuracy and Scale, Island Press, Washington, DC. 
Starfield, A.M. 1997. “A pragmatic approach to modeling for wildlife management,” Journal of Wildlife Management 61: 261-270.

Stinnet, D. and D. Klebenow, 1986. "Habitat use of irrigated lands by California Quail in Nevada." Journal of Wildlife Management, 50: 368-372.

Stith, B.M., J.W. Fitzpatrick, G.E. Woolfenden, and B. Pranty. 1996. "Classification and conservation of metapopulations: a case study of the Florida scrub jay," pp 187-215 in McCullough, D.R., ed., Metapopulations and Wildlife Conservation. Island Press, Washington, DC.

Sweeney, J.M. and W.D. Dijak. 1985. "Ovenbird habitat capability model for an oak-hickory forest." Proceedings of the Annual Conference of the Southeast Association of Fish and Wildlife Agencies 39: 430-438.

Swihart, R.K. and N. A. Slade. 1985. "Testing for independence of observations in animal movements." Ecology 66: 1176-1184.

Swihart, R. and N. Slade. 1997. "On testing of independence of animal movements." Journal of Agricultural, Biological, and Environmental Statistics, 2: 48-63.

Thomas, D.L. and E.J. Taylor. 1990. "Study designs and tests for comparing resource use and availability." Journal of Wildlife Management, 54: 322-330.

Thomas, K., T. Keeler-Wolf and J. Franklin. 2002. "A comparison of fine- and coarse resolution environmental variables toward predicting vegetation distribution in the Mojave Desert," pp 133- 40 in Scott, M.J., P.J. Heglund and M.L. Morrison, eds., Predicting Species Occurrences: Issues of Accuracy and Scale. Island Press, Washington, DC.

Thompson, S. K. 2002. Sampling. 2nd ed. Wiley, New York.

Toll, D.L. 1984. "An evaluation of simulated Thematic Mapper data and Landsat MSS data for discriminating suburban and regional land use and land cover." Photographic Engineering and Remote Sensing 50: 1713-1724.

Trame, A., S.J. Harper, J. Aycrigg and J. Westervelt. 1997. The Fort Hood Avian Simulation Model: a Dynamic Model of Ecological Influences on Two Endangered Species. USACERL Technical Report 97/ 88. U.S. Army Construction Engineering Research Laboratory, Champaign, IL.

Trani, M. K. 1996. Landscape pattern analysis related to forest wildlife resources. Blacksburg, VA: Ph. D. Dissertation, Virginia Polytechnic Institute and State University. 183 pp

Trani, M.K. 2002. "The influence of spatial scale on landscape pattern description and wildlife habitat assessment,” pp 141-156 in Scott, M.J., P.J. Heglund and M.L. Morrison, eds., Predicting Species Occurrences: Issues of Accuracy and Scale. Island Press, Washington, DC.

Tso, B., and P. M. Mather. 2001. Classification Methods for Remotely Sensed Data. Taylor \& Francis, New York. 
Turchin, P. 1998. Quantitative Analysis of Movement: Measuring and Modeling Population Redistribution in Animals and Plants. Sinauer Associates. Inc., Sunderland, MA.

Urban, D.L. and H.H. Shugart, Jr. 1986. “Avian demography in mosaic landscapes: modeling paradigm and preliminary results,” pp 273-279 in J. Verner, M.L. Morrison, and C.J. Ralph, eds., Wildlife 2000: Modeling Habitat Relationships of Terrestrial Vertebrates. University of Wisconsin Press, Madison, WI.

U.S. Army. 1995. Army Regulation 200-3, Natural Resources - Land, Forest and Wildlife Management. Headquarters, U.S. Army, Washington, DC. 28 February 1995.

U.S. Fish and Wildlife Service (USFWS). 1997. Lesser long-nosed bat recovery plan. Albuquerque, New Mexico.

US Fish and Wildlife Service. 2004. Threatened and endangered species system. http://ecos.fws.gov/tess_public/TESSWebpage.

van Horne, B. 1983. "Density as a misleading indicator of habitat quality." Journal of Wildlife Management, 47: 893-901.

van Horne, B. 2002. "Approaches to habitat modeling: the tensions between pattern and process and between specificity and generality," pp 63-72 in Scott, M.J., P.J. Heglund and M.L. Morrison, eds., Predicting Species Occurrences: Issues of Accuracy and Scale. Island Press, Washington, DC.

van Manen, F.T., J.D. Clark, S.E. Schlarbaum, K. Johnson and G. Taylor. 2002. "A model to predict the occurrence of surviving butternut trees in the southern Blue Ridge Mountains," pp 491-498 in Scott, M.J., P.J. Heglund and M.L. Morrison, eds., Predicting Species Occurrences: Issues of Accuracy and Scale. Island Press, Washington, DC.

Vickery, P.D., M.L. Hunter, Jr., and J.V. Wells. 1992. "Is density an indicator of breeding success?" Auk 109: 706-710.

Verbyla, D.L. and J.A. Litvaitis. 1989. "Resampling methods for evaluating classification accuracy of wildlife habitat models." Environmental Management 13: 783-787.

Walker, R.S., A.J. Novaro and L.C. Branch. 2003. "Effects of patch attributes, barriers, and distance between patches on the distribution of a rock-dwelling rodent (Lagidum viscacia)." Landscape Ecology 18: 185-192.

Waller, R.A. and D.B. Duncan. 1969. "A Bayes rule for the symmetric multiple comparisons problem." Journal of the American Statistical Association 64: 1484-1503.

Walters, J. R., L. B. Crowder, and J. A. Priddy. 2002. "Population viability analysis for redcockaded Woodpeckers using an individual-based model.” Ecological Applications, 12:249260.

White, G.C. 2000. "Population viability analysis: data requirements and essential analyses," pp 288-331 in L. Boitani and T.K. Fuller, eds., Research Techniques in Animal Ecology: Controversies and Consequences. Columbia University Press, New York. 
Whittaker, R.H. 1975. Communities and Ecosystems. MacMillan Press, New York, NY.

Wiens, J.A. 1989. "Spatial scaling in ecology.” Functional Ecology 3: 385-397.

Wiens, J.A., J.T. Rotenberry, and B. van Horne. 1987. "Habitat occupancy patterns of NorthAmerican shrub-steppe birds: the effect of spatial scale.” Oikos 48: 132-147.

Worton, B. J. 1989. "Kernel methods for estimating the utilization distribution in home-range studies.” Ecology 70: 164-168.

Young, J.S. and R.L. Hutto. 2002. "Use of regional-scale exploratory studies to determine birdhabitat relationships,” pp 107-122 in Scott, M.J., P.J. Heglund and M.L. Morrison, eds., Predicting Species Occurrences: Issues of Accuracy and Scale. Island Press, Washington, DC.

Zadeh, L.A. 1994. "Fuzzy logic can help GIS cope with reality.” GIS World, September, pp. 50-53. 


\section{Appendix A: A Checklist for Study Design and Validation Considerations When Evaluating Model Performance}

This list is from Roloff and Kernohan (1999) and is most appropriate for Class II and III models, but it is also worth reviewing for all modeling efforts.

\section{Application of a model to a new location}

1. The model is appropriate to the geographic locations under consideration.

2. Input parameters and depicted relationships coincide with the planning area under consideration.

3. Are there local ecological characteristics that need to be incorporated into the model before it will be useful?

4. Habitat depiction within the model corresponds to the seasonal data available at the site under consideration.

\section{General Study Design for Model Input}

1. Resolution of land or habitat classification is at a biologically relevant scale for the organism and model application of interest.

2. Vegetation sampling must be statistically sound and provide evaluation of the confidence in estimates.

3. Spatial information is quantified from maps or GIS with acceptable accuracy.

4. Inclusion of a complete range of habitat conditions in sampling strategy.

\section{Testing the Model}

1. Identify model assumptions.

2. Identify model input variables. 
3. Identify relationships between variables within model.

4. Develop a mechanism to test or at least substantiate the assumptions, validity of input variables, relationships and output.

5. Calculate the minimum home range for the spatial scale of model output.

\section{Characterization of Organism Response}

1. Identify an indication of population fitness to use as response to habitat.

2. Include the ability to monitor changes in population numbers.

3. Adequate replicates to determine organism response.

4. Field data based on 3 breeding cycles of organism

\section{Documentation of Results}

1. Estimate confidence limits around model output and species response.

2. Maintain the complete, detailed description of all replicate data used in analysis.

3. Evaluate statistical assumptions and power.

4. Document range and distributions of organism response (validation) data compared to model output. 


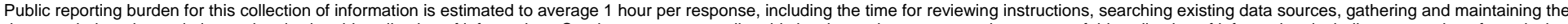

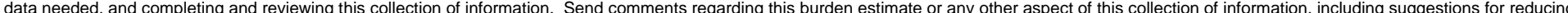

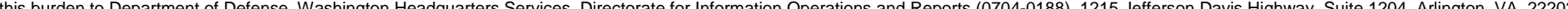

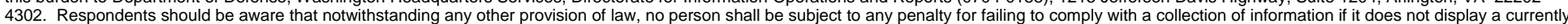
valid OMB control number. PLEASE DO NOT RETURN YOUR FORM TO THE ABOVE ADDRESS.

\section{REPORT DATE (DD-MM-YYYY) 10-2005 \\ 2. REPORT TYPE

Final

4. TITLE AND SUBTITLE

Guidelines for Developing Habitat-based Threatened and Endangered Species Population Goals on Army Installations

\section{AUTHOR(S)}

Ann-Marie Shapiro and Matthew Hohmann
3. DATES COVERED (From - To)

5a. CONTRACT NUMBER

5b. GRANT NUMBER

5c. PROGRAM ELEMENT NUMBER

5d. PROJECT NUMBER

622720A896

5e. TASK NUMBER

5f. WORK UNIT NUMBER

008B44

8. PERFORMING ORGANIZATION REPORT NUMBER

ERDC/CERL TR-05-30

U.S. Army Engineer Research and Development Center (ERDC)

Construction Engineering Research Laboratory (CERL)

PO Box 9005

Champaign, IL 61826-9005

\section{SPONSORING I MONITORING AGENCY NAME(S) AND ADDRESS(ES)}

Office of the Director of Environmental Programs

600 Army Pentagon

Washington, DC 20310-0600

10. SPONSOR/MONITOR'S ACRONYM(S)

DAIM-ED

11. SPONSOR/MONITOR'S REPORT NUMBER(S)

\section{DISTRIBUTION I AVAILABILITY STATEMENT}

Approved for public release; distribution is unlimited.

\section{SUPPLEMENTARY NOTES}

Copies are available from the National Technical Information Service, 5285 Port Royal Road, Springfield, VA 22161.

\section{ABSTRACT}

This document provides an overview of species-habitat modeling approaches, including recent recommendations and criticisms of model shortcomings. Rather than provide an exhaustive treatment of species-habitat modeling, this report provides enough information that an installation could hire or supervise an expert to conduct appropriate modeling, and anticipate and avoid common pitfalls and errors associated with current approaches. The overview is based on a hierarchical structure for organizing species-habitat modeling approaches. Modeling approaches are grouped into three classes, based on data requirements, effort, expense, technical difficulty, application uses, and output characteristics.

\section{SUBJECT TERMS}

threatened and endangered species military training

\section{SECURITY CLASSIFICATION OF:}

\section{a. REPORT} Unclassified

\section{b. ABSTRACT} Unclassified natural resources management Endangered Species Management Plan (ESMP)

simulation modeling

\begin{tabular}{|c|c|}
$\begin{array}{c}\text { 17. LIMITATION } \\
\text { OF ABSTRACT }\end{array}$ & $\begin{array}{c}\text { 18. NUMBER } \\
\text { OF PAGES }\end{array}$ \\
& \\
SAR & 83 \\
\end{tabular}

19a. NAME OF RESPONSIBLE PERSON Matthew Hohmann

19b. TELEPHONE NUMBER (include area code) (217) 352-6511, ext 5863 